NBER WORKING PAPER SERIES

\title{
SUPPLY VS. DEMAND UNDER AN AFFIRMATIVE ACTION BAN: ESTIMATES FROM UC LAW SCHOOLS
}

\author{
Danny Yagan \\ Working Paper 20361 \\ http://www.nber.org/papers/w20361
NATIONAL BUREAU OF ECONOMIC RESEARCH
1050 Massachusetts Avenue
Cambridge, MA 02138
July 2014

I thank Joseph Altonji, David Card, Raj Chetty, David Cutler, John N. Friedman, Roland Fryer, Claudia Goldin, Joshua Gottlieb, Nathaniel Hilger, Caroline Hoxby, Lisa Kahn, Lawrence Katz, Ilyana Kuziemko, Jessica Laird, Justin McCrary, Sendhil Mullainathan, Jesse Rothstein, Emmanuel Saez, Matthew Weinzierl, and Martin West for their comments. Sarah Abraham, Michel Kim, Amol Pai, and Michael Stepner provided excellent research assistance. The 2012-2013 version of this paper circulated with the title "Law School Admissions under the UC Affirmative Action Ban." The views expressed herein are those of the author and do not necessarily reflect the views of the National Bureau of Economic Research.

NBER working papers are circulated for discussion and comment purposes. They have not been peerreviewed or been subject to the review by the NBER Board of Directors that accompanies official NBER publications.

(C) 2014 by Danny Yagan. All rights reserved. Short sections of text, not to exceed two paragraphs, may be quoted without explicit permission provided that full credit, including $\mathbb{C}$ notice, is given to the source. 
Supply vs. Demand under an Affirmative Action Ban: Estimates from UC Law Schools

Danny Yagan

NBER Working Paper No. 20361

July 2014, Revised December 2015

JEL No. I0,J0,K0

\begin{abstract}
Affirmative action bans can reduce black enrollment not only by reducing black admission advantages (contracting demand) but also by reducing applications (contracting supply) from black students who can still gain admission but prefer alternative schools that still practice affirmative action. When affirmative action was banned at UC law schools, Berkeley's black applications and enrollment declined by almost half even as black admission rates rose relative to whites. I ask whether black enrollment at UC law schools would have markedly declined even without the supply contraction. I find in a large sample of students applying to law schools nationwide that black supply contractions were driven mostly or entirely by students unlikely to gain admission under the ban, yielding stronger post-ban black applicant pools. Holding applicant pools constant, I estimate that the ban reduced black admission rates at both Berkeley and UCLA by half. Hence, black enrollment at these elite schools would likely have plummeted even if supply contractions had been muted---as could occur under a nationwide ban that eliminates affirmative-action-practicing alternatives.
\end{abstract}

Danny Yagan

Department of Economics

University of California, Berkeley

530 Evans Hall, \#3880

Berkeley, CA 94720

and NBER

yagan@berkeley.edu 


\section{Introduction}

Black students in the United States would be substantially underrepresented at elite universities if admission decisions were made purely on the basis of academic credentials and without regard to race (Kane 1998; Bowen and Bok 2000; Espenshade, Chung, and Walling 2004; Rothstein and Yoon 2008). Elite universities that value diversity therefore practice affirmative action: awarding admission advantages to black applicants on the basis of race. However, affirmative action is in legal jeopardy: seven states have banned the practice at their public universities, and the U.S. Supreme Court has indicated that it expects to broaden these bans nationwide by $2030{ }^{1}$

Affirmative action bans can reduce black enrollment through two related channels. First, affirmative action bans increase the opportunity cost of admitting black students by weakening the racial information that schools can use in admissions and thereby increasing the non-racial student strength that schools must forgo. The higher opportunity cost can induce schools to contract demand in the form of reduced black admission advantages (Chan and Eyster 2003; Fryer, Loury, and Yuret 2007; Epple, Romano, and Sieg 2008). ${ }^{2}$ Second, a demand contraction of any size can reduce the value to black students of attending an affected school (e.g. due to smaller black campus communities), inducing a supply contraction in the form of reduced applications even from black students who can still gain admission but prefer alternative schools that still practice affirmative action (Long 2004; Card and Krueger 2004 and 2005; Dickson 2006). ${ }^{3} \quad$ Separating supply and demand effects can be crucial for modeling consequences of a nationwide affirmative action ban that eliminates affirmativeaction-practicing alternatives and thus can mute supply responses (Arcidiacono 2005; Epple, Romano, and Sieg 2008). I separate these effects in the context of the first and largest ban - the 1996 University of California affirmative action ban — at the UC's elite law schools Berkeley and UCLA, which experienced extraordinary contractions in black applications after the ban. ${ }^{4}$

Figure 1 motivates the analysis using public aggregates. It shows that after a transition period, the ban permanently reduced the black share of Berkeley's applicant pool by $47.7 \%$ even as black admission rates rose slightly relative to white admission rates - resulting in Berkeley's black enrollment share falling by $40.0 \%$ (as yield rates changed little). ${ }^{5}$ The demand-centric explanation of these effects would

\footnotetext{
${ }^{1}$ The most recent Supreme Court decision on affirmative action (Grutter $v$. Bollinger 2003) concluded with the widely quoted warning "We expect that 25 years from now [in 2028], the use of racial preferences will no longer be necessary to further the interest approved today" because "race-conscious admissions policies must be limited in time." The Court has just heard new oral arguments in the affirmative action challenge Fisher v. Texas (December 2015).

${ }^{2}$ See Appendix A.i for a simple model.

${ }^{3}$ See Appendix A.ii for the simple model of Card and Krueger (2004).

${ }^{4}$ All references to Berkeley and UCLA pertain to their law schools.

${ }^{5}$ Changes are measured 1992-1995 to 2000-2003. Yield rates (the shares of admitted students who enrolled) did not change differentially across races (see the figure notes). UCLA exhibited similar declines in the black share of enrollees $(48.7 \%)$ and the applicant pool (38.3\%) though black admission rates fell relative to white admission rates, underscoring
} 
be that Berkeley substantially contracted demand for black students and that only less-credentialed black students stopped applying, due to expected rejection. A nationwide ban would therefore also be expected to substantially reduce elite black enrollments. In contrast, the supply-centric explanation would be that Berkeley barely contracted demand for black students, but black students of all credential levels nevertheless stopped applying in favor of "black-friendlier" schools with slightly higher racial diversity. A nationwide ban may therefore have little effect on elite black enrollments, as no blackfriendlier schools exist. This paper asks: would UC black enrollments have markedly declined even if black students had not stopped applying?

I address this question using a large sample of applicants to UC and non-UC law schools. I find that black supply contractions were very concentrated among students unlikely to gain admission under the ban, yielding stronger post-ban black applicant pools. After controlling for selective attrition from applicant pools, I robustly estimate that the ban reduced the black admission rate in this sample in half at both Berkeley and UCLA. Hence based on this sample, black enrollment at these elite schools would likely have declined dramatically even if black students had not stopped applying.

Economically, one can understand the results as follows. Affirmative action bans weaken the racial information that can be used in admissions, which increases the non-racial student strength that schools must forgo in order to admit each additional black student. UC schools responded to this higher opportunity cost by collecting race-correlating information like diversity essays and maintained a selection-corrected black admission rate (31\%) well above the rate that would prevail under pre-ban white admission standards (8\%). But UC schools nevertheless substantially contracted demand for black students: the $31 \%$ selection-corrected post-ban black admission rate was still only half the $61 \%$ pre-ban rate. On the supply side, highly credentialed black students continued to apply (exhibiting no significant change) relative to less-credentialed black students (exhibiting a $\square 42 \%$ change). This pattern is consistent with supply responding less to campus racial diversity than to one's own admission probability, with fixed per-school application costs. Colloquially, the results are consistent with black students still wanting to attend UC schools but simply not being able to get in anymore.

The findings are local to and made possible by administrative application-level data on all 25,499 applications submitted to law schools nationwide between 1990 and 2006 by 5,353 undergraduates from one elite college. The dataset's information on the application behavior of non-UC applicants and on the admission decisions of both UC and non-UC applicants permits this paper's joint analysis of supply and demand under the UC ban. The data contain only 185 applications of black students to UC schools, but the key specifications are nevertheless sufficiently statistically powerful because the limited informativeness of public aggregates; see Online Appendix Figure 1. 
law school admissions are unusually formulaic and because effects are large. Omitted variables bias is possible but minimized in this context because the observed covariates are such powerful predictors of admission and because the dataset's thousands of independent screens - admission decisions of UC applicants at non- $U C$ schools - provide a unique opportunity to control for an inferred measure of not-directly-observed applicant strength (e.g. recommendation letters), similar to Dale and Krueger (2002).

The results contribute to a large empirical literature on affirmative action bans. On the supply side, Card and Krueger (2005) and Dickson (2006) find no enduring response of minority applicationsneither overall nor among highly credentialed minorities - to California's and Texas's bans, respectively, based on high-school student SAT submission data. ${ }^{6}$ My paper studies a context with a huge and enduring overall black application response, which therefore provides an especially ripe opportunity to identify supply responses that could be driving large black enrollment declines. On the demand side, Long and Tienda (2008), Arcidiacono, Aucejo, Coate, and Hotz (2014), and Antonovics and Backes (2014) also use administrative data to study admissions under an affirmative action ban. I break from their work by using data on students who applied to both affected and unaffected schools in order to study both supply and demand as well as to address selection on unobserved characteristics like recommendation letter strength. I also study professional school admissions, which spawned the two landmark Supreme Court cases upholding affirmative action (University of California v. Bakke 1978; Grutter v. Bollinger 2003).

Finally, the selective response of black applications provides a key empirical moment to match in structural simulations of a nationwide affirmative action ban at law schools and related settings (Arcidiacono 2005; Epple, Romano, and Sieg 2008). My admissions results further suggest that such simulations should assume neither full elimination of black admission advantages - as assumed in Krueger, Rothstein, and Turner (2006) and Rothstein and Yoon (2008)—nor fully sustained advantages - as assumed in Fryer, Loury, and Yuret (2007). A midpoint between those extremes may be more reasonable.

The remainder of the paper is organized as follows. Section II describes the UC affirmative action ban. Section III introduces the data. Section IV presents the results. Section V concludes.

\footnotetext{
${ }^{6}$ Long (2004) finds no overall response to Texas's ban but a negative overall response to California's ban in 1999 , which Card and Krueger find was small ( $\square 1.3 \%$ ) and short-lived (insignificant and near-zero in 2000 and 2001 ).
} 


\section{Legal and Institutional Environment}

\section{II.A Legal Environment}

On November 5, 1996, California became the first state to ban affirmative action - awarding admission preference to underrepresented minorities on the basis of race - when voters approved Proposition 209 to amend the state constitution to read: "The state shall not discriminate against, or grant preferential treatment to, any individual or group on the basis of race, sex, color, ethnicity, or national origin in the operation of public employment, public education, or public contracting." In particular, no University of California applicant is to be preferred to another on the basis of race. The ban went into effect immediately at UC law schools. ${ }^{7}$ Six other states have since passed similar bans. ${ }^{8}$

Legally, the UC affirmative action ban prohibits the use of race in choosing among applicants but permits the use of applicant characteristics that correlate with race as long as those characteristics have defensible non-racial justification if challenged in court. For example, UC schools are free to use of low family income (which correlates with black status) because broadening socioeconomic access is considered to be independently valuable to universities, but the use of participation in a black-focused extracurricular group would almost certainly be considered illegal. Law school admission decisions are made by a small group of selectors applying subjective criteria with little transparency, so the actual information used is unknown. UC schools (which refer throughout this paper to Berkeley and UCLA law schools) were not bound by any other new laws. ${ }^{9}$

Nationally, the U.S. Supreme Court in 5-4 rulings in both 1978 (Regents of the University of California v. Bakke) and 2003 (Grutter v. Bollinger) upheld the federal constitutionality of affirmative action, keeping the practice legal at all public universities not subject to a statewide ban. The Court's rationale is that although the U.S. Constitution guarantees equal protection to all races under the law, "the educational benefits that flow from a diverse student body" are a "compelling governmental interest" that justifies the use of race when there are no "workable race-neutral alternatives that will achieve the diversity the university seeks" (Grutter). However, the Court concluded Grutter with the widely quoted warning "We expect that 25 years from now [in 2028], the use of racial preferences will no longer be necessary to further the interest approved today" because "race-conscious admissions

\footnotetext{
${ }^{7}$ The ban went into effect one year later at UC undergraduate campuses. The state constitutional amendment superceded the 1995 UC Board of Regents SP-1 resolution, which would have ended affirmative action beginning in 1997 and was later repealed to no legal effect.

${ }^{8}$ The six other states currently under affirmative action bans are Arizona, Florida, Michigan, Nebraska, New Hampshire, and Washington. Georgia and Texas had temporary bans.

${ }^{9}$ Soon after the ban, the State of California guaranteed that high school seniors graduating in the top $4 \%$ of their high schools would gain admission to at least one UC campus but not necessarily the one of their choice. With eight UC campuses, this had little binding effect on undergraduate admissions at the elite campuses of Berkeley and UCLA. No such guarantee applied to law school admissions.
} 
policies must be limited in time." The Court recently heard oral arguments in Fisher v. Texas, widely reported to bode poorly for affirmative action's future. ${ }^{10}$

Affirmative action is currently legal at all private universities but affirmative action may in principle be banned there too, such as through restrictions on all federal-aid-receiving universities. Perhaps as a result, most of the nation's top private universities petitioned the Court in 2003 in detailed amicus briefs to keep it legal at public universities.

\section{II.B Institutional Responses}

A large theoretical literature predicts that affected schools may respond to an affirmative action ban by shifting admissions weight to legal black-correlates, at least partially sustaining pre-ban black enrollment levels (see Appendix A). Consistent with that prediction, UC application forms changed immediately after the ban. Beginning in 1996, application forms have stated that race is not a criterion for admission, and the page requesting applicant race has been diverted to a UC statistical department and not reported to admission offices. Application forms instead solicited new written information that correlates with race (law school applicants are rarely interviewed). For example before the ban, Berkeley gave applicants ten short unconnected prompt options for the personal statement, eight of which did not refer to diversity or disadvantages. Immediately after the ban and ever since, all ten were replaced by a single lengthy one that invited applicants to discuss their contributions to "the diversity of the entering class" and their backgrounds including "a personal or family history of cultural, educational, or socioeconomic disadvantage" (see Online Appendix Figure 2). In 1998, Berkeley added a full-page socioeconomic questionnaire to its application form requesting information such as college attendance rates of high-school friends and whether the applicant was raised by a single parent. Beginning in 2001, UCLA solicited declarations of interest in a Critical Race Studies program and instituted admission preference for interested applicants.

The schools' diversity preferences likely changed little after the ban. UC administrators strongly opposed the ban before it passed and were not systematically replaced after it passed. As the California political climate turned against affirmative action in 1995, the UC president, UC vice-presidents, and the chancellor of each UC campus united to "unanimously urge, in the strongest possible terms," the continuation of affirmative action. ${ }^{11}$ Berkeley's dean added "The need to diversify the legal profession is not a vague liberal ideal: it is an essential component to the administration of justice." ${ }^{2}$ The day

\footnotetext{
${ }^{10}$ See for example the article "Supreme Court Justices' Comments Don't Bode Well for Affirmative Action" (http://www.nytimes.com/2015/12/10/us/politics/supreme-court-to-revisit-case-that-may-alter-affirmativeaction.html).

${ }^{11} 1995$ "Statement Supporting Affirmative Action by UC President, Chancellors, and Vice Presidents", http://www.development.umd.edu/Diversity/Response/Action/policy.

${ }^{12} 1995$ press release, http://www.berkeley.edu/news/berkeleyan/1995/0524/regents.html.
} 
after voters approved the ban, the UC president announced that the question facing the university was "How do we establish new paths to diversity consistent with the law?"13 One year after the ban, Berkeley's dean launched an audit of policies and procedures "to see whether we can achieve greater diversity" after "dire" admission results. ${ }^{14}$ Berkeley's dean and the UC president continued in their posts through 2000 and 2003, respectively. Christopher Edley, a vocal proponent of affirmative action and adviser to President Bill Clinton on the topic, served as Berkeley's dean from 2004 to 2013. Other institutional features like the number of first-year enrollees remained nearly unchanged.

\section{Data}

\section{III.A Source, Basic Variables, and Sample Restrictions}

This paper's primary dataset-which I call the Elite Applications to Law School (EALS) — comprises administrative application-level data on $67 \%$ of an elite college's seniors and graduates (collectively referred to here as "students") who applied to law schools nationwide between the fall of 1990 and the fall of 2006. Applications to every U.S. law school are submitted through the Law School Admissions Council, which records application information and the admission decision for every application filed. ${ }^{15}$ Two-thirds of applicants choose to release their data to their colleges' administrators, and I obtained and digitized seventeen years of a single college's data. The college is elite, is not on the west coast, and has never been subject to an affirmative action ban. Subsection B investigates possible selection over time into the EALS, and Section IV estimates and accounts for selection over time into the Berkeley and UCLA applicant pools.

The EALS contains six variables for each application: student race, LSAT test score (integers between 120 and 180), undergraduate grade point average (GPA) to two decimal places on a 4.00 scale, application year, law school submitted to, and admission decision. I standardize LSAT and GPA to each have mean zero and standard deviation one across students. Motivated semi-parametrically in Subsection $\mathrm{C}$ and used below in Figure 3, I summarize applicants' LSAT and GPA scores with a scalar measure that I call "academic strength" equal to the standardized sum of standardized LSAT and standardized GPA, similar to the rescaling that Kling, Liebman, and Katz (2007) employ in a different context. Application years 1990-1991 through 2001-2002 as well as 2005-2006 also contain

\footnotetext{
${ }^{13} 1996$ "Letter from President Richard C. Atkinson to the University Community Re: Passage of Proposition 209", http://www.universityofcalifornia.edu/news/ article/20607.

${ }^{14} 1997$ Berkeley press release, http://berkeley.edu/news/berkeleyan/1997/0820/kay.html.

${ }^{15}$ Academic credentials are verified through third-party reports, and race is reported by applicants where dishonest answers are grounds for revocation of an admission offer, expulsion from law school, or disbarment. To the extent that any applicants misreported their race, the EALS race variable nevertheless represents the race that was reported to schools on application forms.
} 
applicant state of permanent residence; for these years, I digitized a California resident indicator for Berkeley and UCLA applications only.

The raw data contain 38,200 applications of 6,072 applicants to 187 law schools. For simplicity I restrict the analysis sample to the $94.3 \%$ of applicants listed as white, Asian, black, or Hispanic and the $78.9 \%$ of applications submitted to UC Berkeley, UCLA, or one of the fifteen most-appliedto schools that were never subject to an affirmative action ban. These fifteen schools correspond closely to the top-ranked law schools according to U.S. News and World Report, so I refer to them only somewhat imprecisely as the "top fifteen non-UC law schools." 16 The 170 other schools received relatively few applications in the EALS and are poor control schools for Berkeley and UCLA because these 170 other schools are less selective. The final seventeen-school EALS sample comprises 25,499 applications submitted by 5,353 applicants. Results reported in the main text restrict to the 17,814 applications from only the 3,774 black or white applicants; the appendix reports results using all races. See Appendix B for additional data-coding details.

\section{III.B Summary Statistics}

Table 1 lists summary statistics. The EALS sample is $61 \%$ white, $10 \%$ black, $19 \%$ Asian, and $10 \%$ Hispanic. Black applicants on average possess LSAT scores and GPA's 1.1 and 1.0 standard deviations lower, respectively, than white applicants. Online Appendix Figures 3a-c use non-parametric densities of these academic characteristics to illustrate the first order stochastic dominance of the black and Hispanic distributions by the white and Asian distributions. This stochastic dominance motivates universities' use of affirmative action in order to achieve more racially diverse cohorts. Online Appendix Figure 3d plots means of academic strength over time by race among EALS applicants; pre-ban and post-ban means are very similar within races, suggesting little differential selection over time into the EALS. Section IV estimates and accounts for differential selection over time into the Berkeley and UCLA applicant pools.

Berkeley received applications from $28 \%$ of all applicants $(1,594$, making it the seventh-mostapplied-to school in this sample) and UCLA received applications from $14 \%$ of all applicants (777, the thirteenth most in this sample); see Online Appendix Table 1 for additional comparisons. These schools received relatively few applications from black students - 60 before the ban and 67 after the ban at Berkeley, and 31 before the ban and 27 after the ban at UCLA - which is unsurprising given the relatively small size of elite professional school cohorts. The EALS nevertheless provides sufficient statistical power because law school admission decisions are largely determined by academic credentials

\footnotetext{
${ }^{16}$ Deviations from U.S. News rankings are usually explained by a lower-ranked school being located in a large city. Berkeley was ranked sixth and UCLA was ranked fifteenth in 2010.
} 
and race and because effects are large.

\section{III.C Race and Admission in the Pre-Ban Cross Section}

To provide a feel for the admissions data and also to motivate the use of a standardized measure of academic strength below in Figure 3, Figure 2a displays the semi-parametric relationship between LSAT, GPA, and admission within race-school-years in the EALS, using a $5 \%$ random sample of all 23,128 applications submitted to non-UC schools (Online Appendix Figure 4 displays the 100\% sample, intelligible only in color). Each application's admission decision is plotted in (LSAT, GPA) space, where each application's LSAT score has been re-centered by the estimated race-school-year fixed effect in order to account for selectivity differences across races, schools, and years. Specifically I fit a probit regression of admission on standardized LSAT (mean zero and standard deviation one), standardized GPA, and school-year-race fixed effects; add each application's estimated school-yearrace effect to its LSAT value; and plot individual application decisions in GPA vs. adjusted LSAT space. Applications above and to the right of the best-fit admission threshold line have high enough LSAT and GPA scores to have a predicted admission probability of more than $50 \%$, while those below and to the left do not. ${ }^{17}$

The best-fit line correctly predicts $89.1 \%$ of all admission decisions, and incorrect predictions are concentrated near the line. The ratio of the coefficients on LSAT and GPA in the underlying probit is 0.95 , indicating that a one standard deviation higher LSAT is about as valuable in the admissions cross section as a one standard deviation higher GPA. When useful for subsequent illustrations, I therefore summarize an applicant's academic strength as the standardized (mean zero, standard deviation one) unweighted sum of standardized LSAT and standardized GPA. Figure 2b confirms that the semi-parametric relationship between academic strength and admission within race-schoolyears is well-approximated by a univariate probit regression of admission on academic strength alone. I refer to such a curve relating admission to academic strength as an admission rule in academic strength.

Figure 2c plots fitted admission rules for blacks and whites in pre-ban Berkeley and UCLA admissions. ${ }^{18}$ For ease of comparison, each school's fitted rules have been shifted horizontally by an additive constant so that the admission probability for whites equals 0.5 at academic strength 0 . The

\footnotetext{
${ }^{17}$ The probit model is $\operatorname{Pr}\left(A D M I T T E D_{i s t r}\right)=\Phi\left(\beta_{1} L S A T_{i}+\beta_{2} G P A_{i}+{ }_{s t r}\right)$ where $i$ denotes an applicant and ${ }_{s t r}$ denotes the school-year-race fixed effects. Adjusted LSAT equals $L S A T_{i}+{ }^{{ }^{s t r}}{ }_{s t r} / \hat{\beta}_{1}$. The slope of the best-fit admission threshold line is 0.95 , equal to $\square \hat{\beta}_{1} / \hat{\beta}_{2}$.

${ }^{18}$ For each school I estimate the probit model $\operatorname{Pr}\left(A D M I T T E D_{i t}\right)=\Phi\left(\beta_{1} A C A D E M I C S T R E N G T H_{i}+\right.$ $\left.\beta_{2} B L A C K_{i}+{ }_{t}\right)$ using pre-ban black and white applications, where $B L A C K_{i}$ is a black indicator and ${ }_{t}$ denotes year fixed effects. This paper focuses on black outcomes for simplicity and statistical power, but results for Hispanics are similar.
} 
graph shows that there are levels of academic strength at each school where blacks were nearly assured admission and whites were nearly assured rejection. Berkeley's black and white admission rules are separated by 1.90 standard deviations of academic strength, implying black status is observed to be worth more than the difference between an A- GPA and a B- GPA for a given LSAT in the pre-ban cross section. ${ }^{19}$ At UCLA, the difference is 1.39 standard deviations. Had pre-ban black applicants to each school been subjected to the observed pre-ban white admission standards, Berkeley's black admission rate is predicted to have been $6 \%$ rather than the actual $57 \%$, and UCLA's to have been 10\% rather than $65 \%$ (documented in Section IV.B below). These black-white differences in the EALS are similar in magnitude to those found in the universe of law school applicants to elite schools like Berkeley and UCLA (Rothstein and Yoon 2008) and in undergraduate admissions (Kane 1998; Bowen and Bok 2000; Espenshade, Chung, and Walling 2004). ${ }^{20}$

\section{III.D Inferred Strength}

The previous subsection showed that LSAT and GPA explain the vast majority of the variation in within-race admission decisions, and the difference-in-differences analysis below will hold applicant pools constant along LSAT, GPA, and race. However, one may yet be concerned in that analysis that there is selection on unobservables, conditional on LSAT and GPA across races and over time. In particular, all top law schools solicit and are believed to value additional applicant characteristics like recommendation letters, leadership experience, and a background of no criminal behavior or academic dishonesty. ${ }^{21}$ I proxy for such commonly-valued unobserved admission determinants using the intuition that if an applicant who is predicted to be rejected based on LSAT, GPA, and race is in fact consistently admitted across schools in the EALS, then this applicant is likely strong on unobserved characteristics like recommendation letters. ${ }^{22}$

Specifically, I construct an inferred strength variable for each application, equal to the mean admission success that a given applicant experienced in her other applications that is not explained by observed characteristics. For each school $s$ in either the pre-ban (1990-1995) or post-ban (1996-2006) era, I fit:

$$
\operatorname{Pr}\left(A D M I T T E D_{i s t}\right)=\Phi\left(\beta_{1} L S A T_{i}+\beta_{2} G P A_{i}+\beta_{3} B L A C K_{i}+\beta_{4} H I S P A N I C_{i}+\beta_{5} A S I A N_{i}+{ }_{t}\right)
$$

\footnotetext{
${ }^{19}$ That is, $\hat{\beta}_{2} / \hat{\beta}_{1}=1.90$ in the underlying Berkeley regression.

${ }^{20}$ Using individual-level data on matriculants but not applications, Rothstein and Yoon estimate that black enrollment at elite law schools would have been $90 \%$ lower under white admission standards.

${ }^{21}$ Admission selection criteria are highly correlated across law schools; Figure 2a showed this to be the case for directly observed applicant characteristics (LSAT, GPA, and race). Characteristics that are valued inconsistently across admissions offices include the applicant's geographic preference and intended legal specialty.

${ }^{22}$ Dale and Krueger (2002) similarly use the rich information embedded in independent screens (admissions decisions at other schools) to estimate the returns to higher education.
} 
where $A D M I T T E D_{i t}$ is an indicator for whether student $i$ 's application in year $t$ earned an admission offer; $B L A C K_{i}, H I S P A N I C_{i}$, and $A S I A N_{i}$ are indicators of racial status; ${ }_{t}$ is a vector of year fixed effects; and $\Phi(\cdot)$ denotes the Normal cumulative distribution function using only the applications submitted to school $s$ in the given era. I use the resulting coefficients to compute a predicted admission probability $\operatorname{Pr}\left(A D M I T T E D_{i s t}\right)$ for each application and compute admission residuals $\varepsilon_{i s t}=$ $A D M I T T E D_{i s t} \square \operatorname{Pr}\left(A D M I T T E D_{i s t}\right)$ for each application. Then for each application ist, I compute inferred strength equal to the leave-out mean of student $i$ 's admission residuals from her applications to schools other than $s:^{23}$

$$
\text { INFERREDSTRENGTH } H_{i s t}=\overline{\varepsilon_{i s^{\prime} t}}, s^{\prime} \neq s .
$$

Note that this leave-out-mean formula uses information only from independent screens (admission decisions at schools other than $s$ ) to assign the inferred strength value for the applicant's application to school $s$. When using inferred strength in student-level regressions of the decision to apply to UC schools in Section IV.A, I compute each student's inferred strength as the average of inferred strength across the student's applications.

Inferred strength ranges from $\square 1$ to 1 and is positive for applications submitted by students with relatively weak direct observables who were nevertheless accepted at other schools. Likewise, inferred strength is negative for applications submitted by students with relatively strong observables who were nevertheless rejected at other schools. ${ }^{24}$ Online Appendix Figure 5 demonstrates the predictive power of the inferred strength variable using the full sample of applications by plotting the strongly upward-sloping non-parametric relationship between admission and inferred strength, conditional on LSAT, GPA, and school-year fixed effects.

\section{Results}

This section uses the EALS to estimate the effect of the UC affirmative action ban on applications to and admissions at Berkeley and UCLA. All estimates are local to the EALS. I begin by investigating the application (supply) response to the ban, finding that black student attrition from UC applicant pools was driven by less-credentialed black students. This implies that the UC's average black

\footnotetext{
${ }^{23}$ That is, INFERREDSTRENGTH $H_{i s t}=\frac{1}{S_{i} \square 1} \sum_{s^{\prime}=1, s^{\prime} \neq s}^{S_{i t}} \varepsilon_{i s^{\prime} t}$, where $S_{i t}$ equals the total number of schools applied to by student $i$ in year $t$ and where the schools applied to by applicant $i$ in year $t$ are indexed 1 to $S_{i t}$. To flexibly handle the small share of applicants who applied to only one school, I assign their applications inferred strength equal to zero and include an indicator for these applicants in all regressions where inferred strength is used.

${ }^{24}$ For example, consider a student who applied to Berkeley, Harvard, and Northwestern; who had an admission probability of 0.25 at Harvard and 0.75 at Northwestern based on her LSAT, GPA, and race and the selectivity at Harvard and Northwestern in the given application year; and who was admitted at both Harvard and Northwestern. This candidate's application to Berkeley would be assigned an inferred strength value of $0.5(=[(1 \square .25)+(1 \square .75)] / 2)$.
} 
applicant has become more highly credentialed, so raw admission rate changes that do not control for selective attrition from applicant pools (like those shown in Figure 1) can fail to reflect changes in black admission advantages. I then correct for selective attrition to estimate the paper's main object of interest: the admissions (demand) response to the ban. I robustly find that the ban cause a large reduction in black admission advantages at UC schools. However, large observed cross-sectional black admission advantages remain.

\section{IV.A Applications (Supply)}

I test for effects of the UC affirmative action ban on the likelihood that EALS black students applied to each UC law school by fitting probit models based on the following DD specification:

$$
\operatorname{Pr}\left(A P P L I E D_{i t}\right)=\Phi\left(\mathbf{X}_{i} \boldsymbol{\alpha}+\beta_{1} B L A C K_{i}+\beta_{2} B L A C K_{i} \times P O S T_{t}+{ }_{t}\right)
$$

using black and white students, where $A P P L I E D_{i t}$ is an indicator for whether student $i$ in year $t$ submitted an application to the UC school being studied; $B L A C K_{i}$ is an indicator of black racial status; $P O S T_{t}$ is an indicator for the application being submitted after the ban; $\mathbf{X}_{i}$ is a vector containing LSAT score, GPA, inferred strength, and potentially other covariates linearly, depending on the specification; $t$ is a vector of year fixed effects; and $\Phi(\cdot)$ denotes the Normal cumulative distribution function. ${ }^{25}$ The coefficient $\beta_{2}$ is the coefficient of interest: the effect of the ban on the likelihood that a black student applied to the UC school being studied. Reported coefficients are marginal effects averaged over the right-hand-side characteristics of pre-ban black students, accompanied by robust standard errors (the dataset comprises one observation per student).

Table 2 column 2 presents the results for the whether the applicant applied to Berkeley (panel A) or UCLA (panel B). Panel A reports that the ban reduced application rates to UC Berkeley among black students in the EALS by 9.3 percentage points with a t-statistic of 2.6 and equal to a $34.7 \%$ decline relative the actual pre-ban mean among black students of 26.8 percentage points. Panel B shows an identical effect size in percentage terms (34.4\%) at UCLA. These effect sizes are comparable to those shown for the full Berkeley and UCLA applicants pools (47.7\% and 38.3\%) in Figure 1 and Online Appendix Figure 1.

Columns 3-5 presents results by whether black students could still be expected to be admitted with high probability — which cannot be studied using public aggregates. Column 3 replicates the regression underlying column 2 while including two additional covariates that divide students by a

\footnotetext{
${ }^{25}$ Results are similar when including Hispanics and Asians along with Hispanic and Asian indicators, or when omitting inferred strength. Application probabilities can be non-monotonic in the controls but including higher orders of the controls barely changes the results. Basic ordinary least squares are also reported.
} 
composite measure of applicant strength: an indicator for whether the student had at least a $99 \%$ predicted probability of admission to the given UC school (under pre-ban standards based on preban estimation of equation 1 with admission as the dependent variable, as in column 7 introduced below), as well as the interaction between this "highly credentialed" indicator and the black-x-postban indicator. ${ }^{26}$ Using pre-ban admission standards to categorize students has the property that the categorization is not endogenous to the policy change. For interpretation, highly credentialed post-ban black students (32.0\% of all black EALS students for Berkeley and $43.5 \%$ for UCLA) were on average still quite likely to be admitted post-ban: a $67.3 \%$ admission probability at Berkeley and $91.8 \%$ at UCLA based on post-ban estimation of the column 7 regression. In contrast, nonhighly-credentialed ("less-credentialed") post-ban black applicants had on average a 9.1\% admission probability at Berkeley and $17.9 \%$ at UCLA.

The coefficients in panel A column 3 indicate that the large negative effect on black applications reported in column 2 was driven entirely by less-credentialed black applicants. Highly credentialed black applicants are estimated to have been insignificantly 2.7 percentage points more likely to apply post-ban. In contrast, less-credentialed black applicants were significantly 14.2 percentage points less likely to apply (t-statistic of 3.6 ), equal to a $\square 48.0 \%$ change relative to this sub-group's pre-ban mean application rate of $29.6 \%$. The standard error on the effect among highly credentialed black applicants does not permit rejection of all meaningful response magnitudes, but the heterogeneity in application behavior is clear. Panel B shows similar effects at UCLA, with a percentage change among less-credentialed black applicants of $\square 35.0 \%$ (= $\square 6.0 / 17.4)$. Thus on average across Berkeley and UCLA, the ban reduced applications from less-credentialed black students by $41.5 \%$. Columns 4-5 present alternative specifications that categorize black applicants into those who were quite likely (at least $90 \%$ for column 4 and at least $75 \%$ for column 5 ) to be admitted after the ban, based on post-ban estimation of the regression underlying column $2 .{ }^{27}$ Results are qualitatively similar to those in column 3.

I conclude that there is robust evidence of a large decline in applications to UC schools from lesscredentialed black applicants with no evidence of a decline in applications from highly credentialed black applicants. This implies that the average post-ban black applicant to UC schools was substantially more highly credentialed than the average pre-ban black applicant, relative to contemporaneous white applicants. Hence, raw changes in the black-white admission rate gap (like the one displayed

\footnotetext{
${ }^{26}$ For this categorization, I assume that post-ban students were applying to law schools in 1992 (i.e. I use the 1992 fixed effect) which was an approximately average-selectivity pre-ban year.

${ }^{27}$ For these categorizations, I assume that pre-ban students were applying to law schools in 1999 (i.e. I use the 1999 fixed effect) which was an approximately average-selectivity post-ban year.
} 
in Figure 1) can fail to reflect changes in black admission advantages (demand responses). The next subsection estimates the change in black admission advantages at UC schools by estimating the change in black admission rates, correcting for selective attrition from UC applicant pools.

\section{IV.B Admissions (Demand)}

For simplicity and transparency, I first display the time series of selection-corrected admission rates for black and white applicants at UC and non-UC schools using semi-parametric reweighting on academic strength. Figure 3 displays the time series of black and white admission rates at Berkeley, UCLA, and non-UC schools, where applicant characteristics have been held constant at pre-ban levels using simple semi-parametric reweighting as in DiNardo, Fortin, and Lemieux (1996). To construct the time series of black admission rates at Berkeley, I first compute terciles of academic strength among only pre-ban black applications to Berkeley. Then for each time period shown in the figure, I weight black applications to Berkeley so that each pre-ban-defined tercile receives equal weight when computing the displayed admission rate. ${ }^{28}$ I repeat this process for whites at Berkeley and for whites and blacks separately at UCLA and at each non-UC school, averaging resulting admission rates across non-UC schools to construct the plotted non-UC series. This semi-parametric reweighting is data-demanding, so I reweight on academic strength only and group the data into two pre-ban time periods (1990-1992 and 1993-1995) and two post-ban time periods (1996-2000 and 2001-2006).

The figure shows that at non-UC schools, there was little change over time in the difference between black and white admission rates. At Berkeley the black admission rate rose between 19901992 and 1993-1995 about as much as the white admission rate did, thus exhibiting parallel pre-ban trends. Between 1993-1995 and 1996-2000, the black admission rate fell from $64.4 \%$ to $33.3 \%$ and did not subsequently recover relative to the white admission rate. Figure $3 \mathrm{~b}$ shows a similar decline at UCLA. One can use these reweighted admission rates to compute a simple selection-corrected tripledifference (DDD) estimate of the effect of the ban on the black admission rate at each UC school: $\square 29.9$ percentage points at Berkeley (relative to the actual pre-ban black admission rate of $56.7 \%$ ) and $\square 40.7$ percentage points (relative to the actual pre-ban black admission rate of $64.5 \%$ ). ${ }^{29}$ These declines were much larger than those observed at any non-UC school, so the empirical $p$ value on each of these declines relative to the distribution of changes at non-UC schools is 0 .

Though parsimonious and transparent, Figure 3 does not control for LSAT and GPA separately,

\footnotetext{
${ }^{28}$ That is, each application in time period $T$ with academic strength lying in tercile $G$ receives weight $1 / N_{T G}$, where $N_{T G}$ is the number of applications in the sample submitted to Berkeley in time period $T$ with academic strength in tercile $G$. Quartiles yield similar results; I use terciles because some bin counts are small.

${ }^{29}$ Pooling pre-ban years and separately pooling post-ban years for each series, each DDD estimate is equal to the change in black admission rates at the UC school, minus the change in white admission rates at the UC school and the change in the black-white admission rate difference at non-UC schools. See Online Appendix Table 2 for the arithmetic.
} 
does not control inferred strength or California residency, and does not allow for selection within tercile bins. Table 2 columns 5-9 report regression estimates of the effect of the ban on black admission outcomes at each UC school. The underlying regressions are based on equation (1) using black and white applications to a given UC school and use the dependent variable $A D M I T T E D_{i t}$, which is an indicator for whether student $i$ 's application in year $t$ earned an admission offer. When producing DDD estimates that account for national trends, I include all black and white applications to the topfifteen non-UC schools and interact the second and third terms with an indicator for the application being submitted to a non-UC school. ${ }^{30}$ Standard errors are clustered at the student level. Online Appendix Tables 3-5 replicate Table 2 columns 6-9 using alternative specifications that include all races or control for more interactions.

Column 8 controls for national trends and is my preferred specification. Panel A reports that the ban caused an estimated 33.9 percentage point reduction in black applicants' probability of admission, averaged over the right-hand-side characteristics of pre-ban black applicants and relative to the actual pre-ban black admission rate of 56.7\%. Panel B reports an analogous estimate for UCLA of $\square 33.5$ percentage points, relative to the actual pre-ban black admission rate of $64.5 \%$. These estimates have $t$ statistics of 5.2 and 3.0 respectively. The other columns report similar magnitudes in other specifications, including column 9 which controls for California residency - a UC-specific admission determinant that inferred strength is unlikely to encompass - in the years it is available.

A decline in black admission rates relative to whites opens up space in the admitted cohort for both black and white applicants, implying that the above estimates somewhat overstate the effect of the ban on black admission rates. I therefore compute an adjusted estimate of the effect of the ban on the black admission rate at each UC school by using the UC-specific coefficients of each regression to compute a probit latent variable value for each black and white pre-ban application according to post-ban criteria and then add a constant to every application's value until the mean predicted admission probability across applications equals the actual admission rate observed among these applications. ${ }^{31}$ The resulting estimates are reported in the bottom row of each panel of Table 2 column 8: $\square 30.0$ percentage points at Berkeley and $\square 30.2$ percentage points at UCLA. These are my preferred estimates of the effect of the ban on UC black admission rates in the EALS. These

\footnotetext{
${ }^{30}$ The DDD specification is $\operatorname{Pr}\left(A D M I T T E D_{i s t}\right)=\Phi\left(\mathbf{X}_{i} \boldsymbol{\alpha}+\beta_{1} B L A C K_{i}+\beta_{2} B L A C K_{i} \times P O S T_{t}+\beta_{3} B L A C K_{i} \times\right.$ $\left.U C_{s}+\beta_{4} B L A C K_{i} \times P O S T_{t} \times U C_{s}+{ }_{s t}\right)$, where $U C_{s}$ is an indicator for whether the application was submitted to the UC school being analyzed and ${ }_{s t}$ is a vector of school-year fixed effects. I weight applications so that each school carries equal weight in each time period (pre-ban and post-ban).

${ }^{31}$ Adding a constant varies selectivity uniformly across applications (i.e. preserves application rank). I obtain similar results under the similar method of using the UC-specific coefficients to rank pre-ban applications and then admitting the $N$ highest-ranked applications, where $N$ equals the total number of black and white pre-ban EALS applicants that the UC school admitted.
} 
declines were much larger than those estimated at any individual non-UC school, so the empirical $p$ value of each of these estimates is 0. Averaging these DDD estimates across Berkeley and UCLA, I conclude that the ban reduced the black admission rate from $60.6 \%$ to $30.5 \%$ in the EALS when holding applicant pools constant.

Online Appendix Table 4 replicates Table 2 columns 6-9 using applications from all races (white, black, Hispanic, and Asian); the results are very similar to those in Table 2. Online Appendix Table 5 replicates Online Appendix Table 3 while also fully interacting covariates $\mathbf{X}_{i}$ with race indicators, the post-ban indicator, and the non-UC indicator; the DD results are somewhat larger in magnitude (more negative) than those in Table 2.

As a benchmark for the large effect sizes estimated above, I estimate the black admission rate that would prevail under observed pre-ban white admission standards - i.e. the black admission rate that would prevail if ban simply eliminated cross-sectional black admission advantages. Specifically, I estimate the cross-sectional analogue to equation (1) for each UC school among pre-ban black and white applications:

$$
\operatorname{Pr}\left(A D M I T T E D_{i t}\right)=\Phi\left(\mathbf{X}_{i} \boldsymbol{\alpha}+\beta_{1} B L A C K_{i}+{ }_{t}\right)
$$

where $\mathbf{X}_{i}$ is a vector of LSAT, GPA, and inferred strength and ${ }_{t}$ are year fixed effects. ${ }^{32}$ I then use only the estimated coefficient vector $\hat{\boldsymbol{\alpha}}$ and the year fixed effects to compute a probit latent variable value for each application. Finally to account for the fact that a decline in the black admission rate opens up space in the admitted cohort, I add a constant to every application's value until the mean predicted admission probability across applications equals the actual admission rate among these applications.

Columns 1-2 of Table 3a report the results. Whereas Berkeley actually admitted $56.7 \%$ of pre-ban black applicants, I estimate that it would have admitted only $5.6 \%$ under observed white admission standards. For UCLA, the statistics are $64.5 \%$ and $10.4 \%$. Thus averaging across Berkeley and UCLA, I estimate that the black admission rate would have fallen to $8.0 \%$ had both black and white applicants been subjected to the same observed pre-ban white admission standards. Thus in spite of the large effects of the ban, the ban far from eliminated cross-sectional black admission advantages: holding the applicant pool constant at pre-ban levels, post-ban UC schools sustained average black admission advantages over observably similar whites equal to 22.5 percentage points $(=30.5 \% \square 8.0 \%)$. This is consistent with admissions offices either having shifted admissions weight to non-racial black-

\footnotetext{
${ }^{32}$ Results are similar when omitting inferred strength or including Hispanics and Asians in the regression along with Hispanic and Asian indicators.
} 
correlates like family income and diversity essays in post-ban admissions (see Section II.B), or with UC admissions offices having placed uniquely large admissions weight on non-racial black correlates even before the ban and relative to other schools (since I control for inferred strength).

\section{Conclusion}

Affirmative action bans can reduce black enrollment not only by inducing reductions in black admission advantages (demand contractions) but also by inducing reductions in applications (supply contractions) from black students who can still gain admission but prefer alternative schools that still practice affirmative action. I analyzed the case of Berkeley and UCLA law schools which experienced severe declines in black applications, acceptances, and enrollment after the UC affirmative action ban even as black admission rates rose relative to whites at Berkeley. Data on a large sample of UC and non-UC applications as well as on their admission decisions made possible a unique joint analysis of supply and demand responses. I found that black attrition from UC applicant pools was driven mostly or entirely by less-credentialed black applicants who could no longer expect admission, yielding stronger post-ban black applicant pools. After holding applicant characteristics constant at pre-ban levels, I estimated that the ban cut black admission rates in half at both schools.

The results imply that even if supply responses had been muted - as might happen under a nationwide ban that eliminates affirmative-action-practicing alternatives - UC black enrollment would likely still have plummeted. Economically, the demand response is consistent with schools using non-racial admission factors that only partially sustained black admission advantages, in favor of sustaining other admissions objectives: the selection-corrected post-ban black admission rate (31\%) remained well above the rate that would prevail under observed white admission standards (8\%) but was still only half the pre-ban black admission rate (61\%). The supply response is consistent with black students still wanting to attend UC schools despite lower campus racial diversity, but declining to apply if they can no longer get in.

Effects may be different under a nationwide affirmative action ban. Notably, enrollment changes at less-elite schools under a nationwide ban may differ from the UC's experience depending on the cascading behavior of black students who no longer attend elite schools (Arcidiacono 2005; Epple, Romano, Sieg 2008). Less-elite black enrollment would be expected to decline if these new nonelite-attending black students abandon law school altogether, while it can actually increase if they are willing to trade down to lower-ranked schools where they can gain admission even without affirmative action. Hinrichs (2012) finds no effect of affirmative action bans on less-elite undergraduate minority enrollment though with sizeable standard errors; precise estimates of cascading behavior across 
hierarchies of undergraduate and professional schools are a priority for future work.

Finally, the results may bear on judicial debates. The Supreme Court has decided that affirmative action is unconstitutional whenever there are "workable race-neutral [non-racial] alternatives to achieve the diversity the university seeks" (Grutter $v$. Bollinger 2003). ${ }^{33}$ Workability "does not require exhaustion of every conceivable race-neutral alternative...[nor] a university to choose between maintaining a reputation for excellence or fulfilling a commitment to provide educational opportunities to members of all racial groups" but does "require serious, good faith consideration of workable race-neutral alternatives" (Grutter). I find that UC law schools collected and used non-racial alternatives like family income and diversity essays, yet did not use them aggressively enough to keep black admission advantages from plummeting. This indicates by revealed preference that non-racial alternatives are far from workable from these elite law schools' perspectives, potentially bearing on courts' own judgments of workability. ${ }^{34}$

\footnotetext{
33 "Race-neutral alternatives" include the use of non-racial black correlates like family income in admissions.

${ }^{34}$ The ongoing Supreme Court affirmative action case Fisher $v$. Texas centers on this question, in the context of Texas undergraduate admissions. The Court in 2012 returned Fisher to lower courts for strict scrutiny of whether a workable non-racial alternative exists. The Court heard new oral arguments on Fisher in December 2015.
} 


\section{References}

1. Antonovics, Kate and Ben Backes. 2014. "The Effect of Banning Affirmative Action on College Admissions Rules and Student Quality." Journal of Human Resources, 49(2): 295-322.

2. Arcidiacono, Peter. 2005. "Affirmative Action in Higher Education: How Do Admission and Financial Aid Rules Affect Future Earnings?" Econometrica, 73(5): 1477-1524.

3. Arcidiacono, Peter, Esteban Aucejo, Patrick Coate, and V. Joseph Hotz. 2014. "Affirmative Action and University Fit: Evidence from Proposition 209." IZA Journal of Labor Economics, $3: 7$.

4. Bowen, William G., and Derek Bok. 2000. "Chapter 2: The Admissions Process and Race Neutrality." In The Shape of the River, 15-52. Princeton: Princeton University Press, (Orig. pub. 1998).

5. Card, David, and Alan B. Krueger. 2004. "Would the Elimination of Affirmative Action Affect Highly Qualified Minority Applicants? Evidence from California and Texas." National Bureau of Economics Working Paper 10366.

6. Card, David, and Alan B. Krueger. 2005. "Would the Elimination of Affirmative Action Affect Highly Qualified Minority Applicants? Evidence from California and Texas." Industrial and Labor Relations Review, 58(3): 416-434.

7. Chan, Jimmy, and Erik Eyster. 2003. "Does Banning Affirmative Action Lower College Student Quality?" American Economic Review, 93(3): 858-872.

8. Dale, Stacy Berg, and Alan B. Krueger. 2002. "Estimating the Payoff to Attending a More Selective College: An Application of Selection on Observables and Unobservables." Quarterly Journal of Economics, 117(4):1491-1527.

9. DiNardo, John, Nicole Fortin, and Thomas Lemieux. 1996. "Labor Market Institutions and the Distribution of Wages, 1973-1992: A Semiparametric Approach." Econometrica, 64(5): 10011044.

10. Dickson, Lisa. 2006. "Does Ending Affirmative Action in College Admissions Lower the Percent of Minority Students Applying to College?" Economics of Education Review, 25(1): 109-119.

11. Epple, Dennis, Richard Romano, and Holger Sieg. 2008. "Diversity and Affirmative Action in Higher Education." Journal of Public Economic Theory, 10(4): 475-501.

12. Espenshade, Thomas J., Chang Y. Chung, and Joan L. Walling. 2004. "Admission Preferences for Minority Students, Athletes, and Legacies at Elite Universities." Social Science Quarterly, 85(5): 1423-1446.

13. Fryer, Roland, Glenn Loury, and Tolga Yuret. 2007. "An Economic Analysis of Color-Blind Affirmative Action." Journal of Law, Economics, and Organization, 24(2): 319-355.

14. Hinrichs, Peter. 2012 "The Effects of Affirmative Action Bans on College Enrollment, Educational Attainment, and the Demographic Composition of Universities," Review of Economics and Statistics, 94(3): 712-722.

15. Kane, Thomas. 1998. "Racial and Ethnic Preference in College Admissions." In The BlackWhite Test Score Gap, ed. Christopher Jencks and Meredith Phillips, 431-456. Washington: Brookings Institution. 
16. Kling, Jeffrey, Jeffrey Liebman, and Lawrence Katz. 2007. "Experimental Analysis of Neighborhood Effects." Econometrica, 75(1): 83-119.

17. Krueger, Alan B, Jesse Rothstein, and Sarah Turner. 2006. "Race, Income, and College in 25 Years: Evaluating Justice O'Connor's Conjecture." American Law and Economics Review, 8(2): 282-311.

18. Long, Mark. 2004. "College Applications and the Effect of Affirmative Action." Journal of Econometrics, 121(1-2): 319-342.

19. Long, Mark, and Marta Tienda. 2008. "Winners and losers: Changes in Texas university admissions post-Hopwood." Educational Evaluation and Policy Analysis, 30(3): 255-280.

20. Rothstein, Jesse and Albert H. Yoon. 2008. "Affirmative Action in Law School Admissions: What Do Racial Preferences Do?" University of Chicago Law Review, 75: 649-714. 


\section{Appendix A: Models of Demand and Supply under an Affirmative Action Ban}

The first part of this appendix presents a simplified version of earlier models of admissions under an affirmative action ban (Chan and Eyster 2003; Fryer, Loury, and Yuret 2007; Epple, Romano, and Sieg 2008 ) in order to show how a ban can induce a reduction in black admission advantages (a contraction in demand for black students) holding the applicant pool constant. The reduction in black admission advantages is large when legal non-racial admission factors like family income correlate only weakly with race (i.e. when the ban substantially raises the opportunity cost of admitting black students) and when schools are unwilling to sacrifice other objectives in order to sustain costlier racial diversity (i.e. when substitution effects dominate income effects).

The second part reproduces Card and Krueger's (2004) model of application decisions in order to show how a ban can reduce black applications (a contraction in supply of black students). The reduction in black applications from marginal black candidates is large when demand contractions are large. The reduction in black applications from black students of all credential levels is large when black students' utility of attending an affected school substantially declines independently of their individual credential levels - e.g. via lower black campus representation following declines in other black students' applications, acceptances, and enrollment.

(i) Demand Contraction. Consider a school with concave preferences over the number of black enrollees $\bar{r}$ (short for "racial diversity") and the aggregate non-racial strength of enrollees $\bar{q}$ (short for "qualifications"). Each applicant is either black or white, the applicant pool is the same pre-ban and post-ban (abstracting here from supply effects), and all admitted students enroll. The school maximizes utility subject to a binding capacity constraint (it can admit no more than a fixed number $\bar{N}$ of applicants and must reject some applicants):

$$
\max _{\bar{r}, \bar{q}} u(\bar{r}, \bar{q}) \quad \text { s.t. } \quad N(\bar{r}, \bar{q}) \leq \bar{N}
$$

where $N(\bar{r}, \bar{q})$ is the minimum number of applicants that must be admitted in order to deliver $\bar{r}$ black admits and $\bar{q}$ aggregate non-racial strength. $N(\bar{r}, \bar{q})$ is an implicit function of the joint distribution of race and non-racial strength in the applicant pool. The school faces a tradeoff in that the admission rule that maximizes the number of black admits is not the one that maximizes aggregate non-racial strength.

The school can admit applicants $i$ on the basis of two pieces of information: non-racial strength $q_{i}$ and a binary signal $B L A C K S I G N A L_{i} \in\{0,1\}$ of black status. The black signal may be perfect (all black-signaled applicants are black and all white-signaled applicants are white) or diluted (not all black-signaled applicants are black and some white-signaled applicants are black). When diluted, I assume that dilution is orthogonal to non-racial strength. The optimal admission rule can then be characterized as a "rank-and-yank" rule that admits the $\bar{N}$ applicants that have highest rank according to:

$$
R A N K_{i}=q_{i}+\lambda B L A C K S I G N A L_{i}
$$

where $\lambda$ is chosen to maximize utility. This is true because for any number of admitted blacksignaled applicants, the school maximizes aggregate non-racial strength by adopting a threshold rule within each black signal value: only black-signalled applicants with non-racial strength above some

$q_{B L A C K S I G N A L=1}^{*}$ and white-signalled applicants with non-racial strength above some $q_{B L A C K S I G N A L=0}^{*}$ are admitted. Rank-and-yank implements any such pair of threshold rules by setting weight $\lambda$ equal to $q_{B L A C K S I G N A L=0}^{*} \square q_{B L A C K S I G N A L=1}^{*}$.

When affirmative action is not banned, the black signal is perfect. Online Appendix Figure 6a illustrates a feasible pair of optimal admission thresholds and illustrates its consequences for black and white applicants. To define the no-affirmative-action benchmark, let $q^{*}$ be the level of nonracial strength above which there are exactly $\bar{N}$ applicants. This is the race-neutral threshold that 
would maximize aggregate non-racial strength and corresponds to a rank-and-yank admission rule with $\lambda=0$. A school practicing affirmative action chooses $\lambda>0$ and thus adopts a threshold admission rule for blacks at $q_{B L A C K S I G N A L=1}^{*}$ and a separate higher threshold for whites at $q_{B L A C K S I G N A L=0}^{*}>$ $q_{B L A C K S I G N A L=1}^{*}$. Relative to the no-affirmative-action benchmark, the school practicing affirmative action admits extra blacks (the grid fill pattern) and rejects extra whites (the solid fill pattern).

Online Appendix Figure 6c illustrates an affirmative action budget set in $(\bar{r}, \bar{q})$ space for the simple case of uniform distributions of non-racial strength within each race. The range of weights $\lambda \in[0, \infty)$ traces out the affirmative action ("AA") budget constraint. Point A is a potentially optimal bundle under affirmative action. The budget constraint is strictly convex because the first black applicant admitted through affirmative action is almost as strong as the white applicant that is rejected in order to make room. After that, stronger and stronger white applicants are rejected in order to make room for weaker and weaker black applicants.

An affirmative action ban prohibits the school from using a pure signal of race but allows it to use non-racial black-correlates like low family income that have plausible non-racial justification. I model this as dilution of the black signal with fraction $p_{\text {black }}$ of black applicants and fraction $p_{\text {white }}$ of white applicants signaled as black (e.g. those having family income below some threshold), with $p_{\text {black }} \square p_{\text {white }}<1$ and for simplicity $p_{\text {black }}, p_{\text {white }} \perp q_{i}$. The school increasing racial diversity above the no-affirmative-action benchmark now makes "mistakes" in the sense that the school rejects some applicants that have higher non-racial strength than accepted applicants of the same race, as illustrated in Online Appendix Figure 6b. Thus an affirmative action ban raises the opportunity cost of admitting black applicants.

In the analytically tractable case of uniform distributions of non-racial strength within race, ${ }^{35}$ the diluted black signal under an affirmative action ban ("BAN") raises the marginal rate of transformation of admitted blacks for non-racial strength by a factor that is decreasing in the purity of the black signal:

$$
\frac{\operatorname{MRT}_{\bar{r}, \bar{q}}^{B A N}}{M R T_{\bar{r}, \bar{q}}^{A A}}=\frac{1}{\left(p_{\text {black }} \square p_{\text {white }}\right)^{2}}>1
$$

The larger opportunity cost puts the affirmative-action-ban budget set inside the affirmative action budget set, illustrated in Online Appendix Figure 6c. If substitution effects dominate, the school may respond to a ban by substantially contracting demand for black students (e.g. moving to bundle B) - sustaining the non-racial strength of admitted cohorts at the expense of racial diversity. But if income effects dominate, the school may barely contract demand for black students (e.g. moving to bundle $\mathrm{C}$ ) or even increase demand (if preferences are Giffen) - sustaining racial diversity at the expense of non-racial strength. Thus the degree to which a ban reduces black enrollment depends on the degree to which a ban dilutes the usable signal of race in admissions and on the substitutablity of racial diversity for non-racial strength in the school's preferences. ${ }^{36}$

(ii) Supply Contraction. A student has utility $U_{s}$ of attending a school $s$, a probability $P_{s}$ of gaining admission to $s$ conditional on applying, and von Neumann-Morgenstern expected utility. Assume for simplicity that the student's admission decisions across different schools are independent conditional on $P_{s}$. Assume that there is a positive utility cost $d$ of applying to each school, and let $U_{0}$ denote the utility of not attending any school. Let $C$ denote the student's application set, comprising an ordered list of $S$ schools with $U_{1} \leq U_{2} \leq \ldots \leq U_{S}$.

Taking $\left\{U_{s}, P_{s}\right\}$ as given, a student applies to a given school $k$ if and only if the admission probability $P_{k}$ exceeds a $k$-specific threshold. Specifically, let $C(\sim k)$ denote the optimal choice set when

\footnotetext{
${ }^{35}$ Without this or a similar assumption, the budget set can be non-convex over some intervals.

${ }^{36}$ Chan and Eyster (2003) adopt preference and technology restrictions to predict that the post-ban school introduces idiosyncratic noise - an imperfect black signal when black applicants are concentrated at lower levels of the non-racial strength distribution - to admission decisions. Fryer, Loury, and Yuret (2007) analyze the case in which the post-ban school uses non-racial black correlates aggressively enough to admit the same number of black applicants as it did pre-ban.
} 
excluding school $k$ from consideration, with $S(\sim k)$ denoting the number of schools in this set. The student will include $k$ in her final choice set if and only if the expected value of applying to $k$ exceeds the application cost:

$$
P_{k}\left\{\prod_{s=0}^{S(\sim k)} \pi_{s} \max \left[0, U_{k} \square U_{s}\right]\right\}>d
$$

where $\pi_{s}=P_{s} \cdot \Pi_{j=s+1}^{S}\left(1 \square P_{j}\right)$ equals the probability that school $s \in C$ is the highest-utility school she gains admission to and $\pi_{0}=\Pi_{j=1}^{S}\left(1 \square P_{j}\right)$ equals the probability that the student is admitted to no school. ${ }^{37}$ The expected value of applying to school $k$ equals the probability of being admitted to $k$, times the probability that $k$ is the best school she is admitted to.

An affirmative action ban can cause a black student to remove an affected school $k$ from her application set through two channels. ${ }^{38}$ First, the ban can reduce her probability of gaining admission $P_{k}$. In relatively formulaic contexts like law school admissions where students with sufficiently high test scores and grades are virtually guaranteed admission, the reduction in $P_{k}$ may be zero for highly credentialed black students but large for less credentialed black students, inducing selective attrition from $k$ 's applicant pool. Second and to the extent that the student values a larger black student presence on campus, the ban can reduce utility $U_{k}$-via the lower likelihood of other black students applying, gaining admission, and enrolling - and thereby induce the student to remove $k$ from her application set, especially if there are comparable unaffected schools that she can add to her application set. This substitution force (replacing affected schools with unaffected schools) can be arbitrarily large following even a small reduction in black admission advantages and can dissuade applications from black students uniformly across the credential distribution. The substitution force can be arbitrarily small when all schools are affected by the affirmative action ban.

\section{Appendix B: Details of EALS Data Coding}

The first application year's LSAT scores are in a more compact scale than all other years', and I convert them to the modern scale using percentile rank. I de-mean GPA by year to account for modest grade inflation over time. I code "Hispanic", "Chicano/Mexican-American", and "Puerto Rican" as Hispanic. Undergraduate major is available in some years' raw data; it has low statistical power in subsamples and its use would limit the years available for analysis so I omit it. The admission decision for a small percentage of accepted students is classified as rejected when the applicant in fact accepted and deferred an admission offer. The relatively minor importance of this measurement error is suggested visually in Figure $2 \mathrm{~b}$, where actual admission rates are close to $100 \%$ at high levels of academic strength, rather than plateauing at a smaller number. Year of college graduation is available in all years; I omit it from the analysis for simplicity but every qualitative result holds when also controlling for graduation year. The only other information in the raw data are indicators for whether the applicant took the LSAT more than once, whether the applicant withdrew an application before an admission decision was made, and whether the applicant accepted an admission offer. I exclude withdrawn applications from the analysis, and I do not have sufficient power to analyze matriculation decisions.

The raw data do not contain student identifiers, so for each year I create student identifiers by treating as coming from the same student those applications that match on all of the applicationinvariant variables. This is a powerful method for identifying applications submitted by the same student in largest part because GPA is coded to two decimal places. I exclude the fewer than

\footnotetext{
${ }^{37}$ She of course does not apply to any schools dominated by the no-school option.

${ }^{38}$ Not modeled here is the possibility that an affirmative action ban raises a black student's likelihood of applying to an affected school, for example due to potentially higher signal value from gaining admission without affirmative action.
} 
one percent of observations for which this method implies that a single student submitted multiple applications to the same school.

Finally, I do not include the University of Michigan in the group of fifteen most-applied-to schools because it was subject to an affirmative action ban during the sample. I do not analyze Michigan as a treatment school because its bans were effective during the sample only in 2001 and 2006 and I do not have sufficient power to conduct year-by-year difference-in-differences. UC law schools at Davis and Hastings as well as public Texas law schools received few applications in the EALS and similarly do not permit robust inference. 
TABLE 1

Applicant Characteristics by Race

\begin{tabular}{|c|c|c|c|c|}
\hline $\begin{array}{c}\text { Share of } \\
\text { applicants }\end{array}$ & $\begin{array}{l}\text { LSAT score } \\
\text { (sd 6.7) }\end{array}$ & $\begin{array}{c}\text { Undergraduate } \\
\text { GPA } \\
\text { (sd 0.33) }\end{array}$ & $\begin{array}{c}\text { Academic } \\
\text { strength } \\
\text { (mean } 0, \text { sd } 1)\end{array}$ & Admission rate \\
\hline
\end{tabular}

A. All Applicants ( $N=5,353$, collectively submitting 25,499 applications to top-17 schools)

\begin{tabular}{|c|c|c|c|c|c|}
\hline $\begin{array}{l}\text { White } \\
\text { Black } \\
\text { Asian } \\
\text { Hispanic }\end{array}$ & $\begin{array}{c}60.8 \% \\
9.7 \% \\
19.4 \% \\
10.1 \%\end{array}$ & $\begin{array}{l}167.3 \\
159.9 \\
167.6 \\
162.8\end{array}$ & $\begin{array}{l}3.47 \\
3.15 \\
3.52 \\
3.31\end{array}$ & $\begin{array}{c}0.24 \\
-0.98 \\
0.33 \\
-0.48\end{array}$ & $\begin{array}{l}41 \% \\
56 \% \\
41 \% \\
39 \%\end{array}$ \\
\hline
\end{tabular}

B. Applicants to Berkeley $(\mathrm{N}=1,594)$

\begin{tabular}{lccccc}
\hline White & $56.6 \%$ & 167.5 & 3.47 & 0.23 & $31 \%$ \\
Black & $8.0 \%$ & 160.8 & 3.13 & -0.92 & $43 \%$ \\
Asian & $24.2 \%$ & 167.0 & 3.49 & 0.21 & $36 \%$ \\
Hispanic & $11.3 \%$ & 162.3 & 3.31 & -0.53 & $34 \%$
\end{tabular}

C. Applicants to UCLA $(\mathrm{N}=777)$

\begin{tabular}{lccccc}
\hline White & $55.0 \%$ & 165.4 & 3.38 & -0.09 & $54 \%$ \\
Black & $7.5 \%$ & 159.6 & 3.03 & -1.17 & $53 \%$ \\
Asian & $24.5 \%$ & 165.2 & 3.43 & -0.06 & $60 \%$ \\
Hispanic & $13.1 \%$ & 159.8 & 3.23 & -0.89 & $35 \%$
\end{tabular}

Notes - Panel A lists mean student characteristics for the Elite Applications to Law School (EALS) sample used in this paper. The sample comprises the 5,353 students who together submitted 25,499 applications over seventeen years to Berkeley, UCLA, and the top-fifteen law schools that were never subject to an affirmative action ban. LSAT is the standardized test score used in law school admissions and ranges from 120 to 180. Undergraduate grade point average is the cumulative undergraduate GPA on a 4.00 scale. Academic strength is a scalar index of the strength of an applicant's academic credentials, equal to the standardized (mean zero and standard deviation one) sum of standardized LSAT and standardized GPA (see Figure 2) and is used only for Figure 3. Panels B and C list the same statistics for applicants to Berkeley and UCLA, respectively, in the EALS. Online Appendix Table 1 lists summary statistics on application behavior and comparisons to the nationwide population of law school applicants. 
TABLE 2

Effects on Black Application Rates and Selection-Corrected Black Admission Rates

\begin{tabular}{|c|c|c|c|c|c|c|c|c|c|}
\hline \multirow[t]{2}{*}{ Dependent Variable: } & \multicolumn{5}{|c|}{ Applied } & \multicolumn{4}{|c|}{ Admitted } \\
\hline & $\begin{array}{l}(\mathrm{pp}) \\
(1)\end{array}$ & $\begin{array}{l}(\mathrm{pp}) \\
(2)\end{array}$ & $\begin{array}{l}\text { (pp) } \\
(3)\end{array}$ & $\begin{array}{l}(\mathrm{pp}) \\
(4)\end{array}$ & $\begin{array}{l}(\mathrm{pp}) \\
(5)\end{array}$ & $\begin{array}{c}(\mathrm{pp}) \\
(6)\end{array}$ & $\begin{array}{l}(\mathrm{pp}) \\
(7)\end{array}$ & $\begin{array}{l}(\mathrm{pp}) \\
(8)\end{array}$ & $\begin{array}{l}(\mathrm{pp}) \\
(9)\end{array}$ \\
\hline \multicolumn{10}{|l|}{ A. Berkeley } \\
\hline Black $\times$ Post-ban & $\begin{array}{l}-10.5 \\
(4.0)\end{array}$ & $\begin{array}{l}-9.3 \\
(3.6)\end{array}$ & $\begin{array}{l}2.7 \\
(6.1)\end{array}$ & $\begin{array}{c}8.2 \\
(10.0)\end{array}$ & $\begin{array}{c}1.4 \\
(7.2)\end{array}$ & $\begin{array}{l}-39.7 \\
(6.8)\end{array}$ & $\begin{array}{l}-40.0 \\
(5.3)\end{array}$ & $\begin{array}{l}-33.9 \\
(6.5)\end{array}$ & $\begin{array}{l}-43.6 \\
(5.5)\end{array}$ \\
\hline Black $\times$ Post-ban $\times$ Pre-ban-admit-rate $<99 \%$ & & & $\begin{array}{r}-14.2 \\
(4.0)\end{array}$ & & & & & & \\
\hline Black $\times$ Post-ban $\times$ Post-ban-admit-rate $<90 \%$ & & & & $\begin{array}{l}-15.5 \\
(5.4)\end{array}$ & & & & & \\
\hline Black $\times$ Post-ban $\times$ Post-ban-admit-rate $<75 \%$ & & & & & $\begin{array}{l}-11.5 \\
(5.1)\end{array}$ & & & & \\
\hline $\begin{array}{l}\text { Ordinary least squares estimation } \\
\text { Probit estimation } \\
\text { National trend controls } \\
\text { CA residency control }\end{array}$ & $x$ & $\mathrm{X}$ & $\mathrm{X}$ & $\mathrm{X}$ & $x$ & $x$ & $\mathrm{X}$ & $\begin{array}{l}X \\
X\end{array}$ & $\begin{array}{l}x \\
x\end{array}$ \\
\hline $\begin{array}{l}\text { Number of observations } \\
\text { Number of clusters }\end{array}$ & $\begin{array}{l}3,774 \\
3,774\end{array}$ & $\begin{array}{l}3,774 \\
3,774\end{array}$ & $\begin{array}{l}3,774 \\
3,774\end{array}$ & $\begin{array}{l}3,774 \\
3,774\end{array}$ & $\begin{array}{l}3,774 \\
3,774\end{array}$ & $\begin{array}{l}1,029 \\
1,029\end{array}$ & $\begin{array}{l}1,029 \\
1,029\end{array}$ & $\begin{array}{c}17,329 \\
3,754\end{array}$ & $\begin{array}{l}779 \\
779\end{array}$ \\
\hline $\begin{array}{l}\text { Actual pre-ban black dependent variable mean } \\
\Delta \text { implied by Black } \times \text { Post-ban effect }\end{array}$ & 26.8 & 26.8 & 26.8 & 26.8 & 26.8 & $\begin{array}{l}56.7 \\
-34.2\end{array}$ & $\begin{array}{l}56.7 \\
-35.6\end{array}$ & $\begin{array}{l}56.7 \\
-30.0\end{array}$ & $\begin{array}{r}56.7 \\
-39.7\end{array}$ \\
\hline \multicolumn{10}{|l|}{ B. UCLA } \\
\hline Black $\times$ Post-ban & $\begin{array}{l}-5.1 \\
(3.0)\end{array}$ & $\begin{array}{l}-4.8 \\
(2.9)\end{array}$ & $\begin{array}{l}-0.4 \\
(4.3)\end{array}$ & $\begin{array}{l}-0.9 \\
(4.6)\end{array}$ & $\begin{array}{l}-1.9 \\
(4.1)\end{array}$ & $\begin{array}{l}-48.1 \\
(10.5)\end{array}$ & $\begin{array}{l}-35.0 \\
(11.2)\end{array}$ & $\begin{array}{l}-33.5 \\
(11.1)\end{array}$ & $\begin{array}{l}-31.1 \\
(10.5)\end{array}$ \\
\hline Black $\times$ Post-ban $\times$ Pre-ban-admit-rate $<99 \%$ & & & $\begin{array}{l}-6.1 \\
(3.1)\end{array}$ & & & & & & \\
\hline Black $\times$ Post-ban $\times$ Post-ban-admit-rate $<90 \%$ & & & & $\begin{array}{l}-5.0 \\
(3.6)\end{array}$ & & & & & \\
\hline Black $\times$ Post-ban $\times$ Post-ban-admit-rate $<75 \%$ & & & & & $\begin{array}{l}-4.4 \\
(3.5)\end{array}$ & & & & \\
\hline $\begin{array}{l}\text { Ordinary least squares estimation } \\
\text { Probit estimation } \\
\text { National trend controls } \\
\text { CA residency control }\end{array}$ & $x$ & $x$ & $\mathrm{x}$ & $\mathrm{x}$ & $\mathrm{X}$ & $x$ & $\mathrm{X}$ & $\begin{array}{l}X \\
X\end{array}$ & $\begin{array}{l}x \\
x\end{array}$ \\
\hline $\begin{array}{l}\text { Number of observations } \\
\text { Number of clusters }\end{array}$ & $\begin{array}{l}3,774 \\
3,774\end{array}$ & $\begin{array}{l}3,774 \\
3,774\end{array}$ & $\begin{array}{l}3,774 \\
3,774\end{array}$ & $\begin{array}{l}3,774 \\
3,774\end{array}$ & $\begin{array}{l}3,774 \\
3,774\end{array}$ & $\begin{array}{l}485 \\
485\end{array}$ & $\begin{array}{l}485 \\
485\end{array}$ & $\begin{array}{c}16,785 \\
3,736\end{array}$ & $\begin{array}{l}371 \\
371\end{array}$ \\
\hline $\begin{array}{l}\text { Actual pre-ban black dependent variable mean } \\
\Delta \text { implied by Black } \times \text { Post-ban effect }\end{array}$ & 13.8 & 13.8 & 13.8 & 13.8 & 13.8 & $\begin{array}{l}64.5 \\
-41.6\end{array}$ & $\begin{array}{r}64.5 \\
-32.0\end{array}$ & $\begin{array}{c}64.5 \\
-30.2\end{array}$ & $\begin{array}{r}64.5 \\
-29.2\end{array}$ \\
\hline
\end{tabular}

Notes - This table uses black and white students in the EALS to report difference-in-difference estimates of the effect of the UC affirmative action ban on whether a student applied to (columns 1-5) or was admitted at (columns 6-9) Berkeley (panel A) or UCLA (panel B). Standard errors clustered by student (equivalent to robust standard errors in all specification except column 8) are in parentheses, and reported coefficients in probit columns are marginal effects averaged over the UC school's pre-ban black applicant characteristics. All specifications include a black indicator, a black indicator interacted with a post-ban indicator, LSAT test score, undergraduate GPA, inferred strength, and year fixed effects; see Table 1 and Figure 2 for variable definitions. Specifications with national trend controls are triple-difference regressions that control for black and white admission trends at non-UC schools; these regressions include school-year fixed effects and are weighted so that each school receives equal weight in each time period (pre-ban and post-ban). The California residency indicator control is available only for applications to UC schools and in certain years. Column 3 includes two covariates that divide applicants by a composite measure of applicant strength: an indicator for whether the applicant had a $99 \%$ predicted probability of admission to the given UC school based on pre-ban estimation of the column 7 regression, as well as the interaction between this indicator and the black-x-post-ban indicator. Columns 4-5 present alternative specifications that group black applicants into those who were quite likely (at least $90 \%$ for column 4 and at least $75 \%$ for column 5 ) to be admitted after the ban, based on post-ban estimation of the regression underlying column 7. The final row in each panel of columns 6-9 reports estimates of the change in the admission rate that pre-ban black applicants are predicted to have experienced had the ban been in effect, accounting for the minor space-opening effect of a decline in black admission rates (see Section IV.B for details). 
TABLE 3

Black-White Admission Rate Differences in Pre-ban and Post-ban Admissions

\begin{tabular}{|c|c|c|}
\hline $\begin{array}{c}\text { Actual black } \\
\text { admission rate }\end{array}$ & $\begin{array}{l}\text { Hypothetical black } \\
\text { admission rate under } \\
\text { white coefficients }\end{array}$ & $\begin{array}{l}\text { Average conditional } \\
\text { black-white admission } \\
\text { rate difference } \\
\text { (col. } 1 \text { minus col. } 2 \text { ) }\end{array}$ \\
\hline$(\%)$ & (\%) & (pp) \\
\hline (1) & (2) & (3) \\
\hline
\end{tabular}

A. Pre-ban

Berkeley

56.7

5.6

51.1

$[43.6,69.5]$

$[1.2,11.4]$

$[38.7,62.5]$

UCLA

64.5

10.4

54.1

$[46.7,80.6]$

$[2.2,21.0]$

$[37.0,70.5]$

B. Post-ban

\begin{tabular}{lccc}
\hline Berkeley & 31.3 & 13.5 & 17.8 \\
& {$[20.4,43.4]$} & {$[7.1,20.6]$} & {$[9.3,27.0]$} \\
UCLA & 40.7 & 21.1 & 19.6 \\
& {$[23.1,60.0]$} & {$[7.9,37.6]$} & {$[6.2,34.1]$} \\
\hline \hline
\end{tabular}

Notes - Each cell reports an estimate of either a black admission rate or a black-white admission rate difference using the EALS dataset. Ninety-five percent confidence intervals are computed using one thousand bootstrapped samples of each school-time period and are listed in brackets. Only black and white applications are used. Column 1 lists the actual black admission rate in the specified school-time period. Column 2 reports the black admission rate that is predicted to have prevailed if black applicants had been subjected to observed white admission standards, calculated by estimating a probit regression of admission on LSAT, GPA, inferred strength, a black indicator, and year fixed effects and then using the coefficients other than on the black indicator to predict admission probabilities for each applicant and accounting for the minor spaceopening effect of a decline in black admission rates. Reported estimates are means of these predicted admission probabilities. Column 3 equals the difference between columns 2 and 1 and is an estimate of the average black-white admission rate difference for this school-time period's black applicants, conditional on covariates. 


\section{ONLINE APPENDIX TABLE 1 Application Behavior and Comparison of Applicant Characteristics}

\begin{tabular}{|c|c|c|c|}
\hline \multicolumn{4}{|c|}{ A. Application Behavior in the Full EALS, 1990-2006 } \\
\hline \multicolumn{3}{|c|}{$\begin{array}{l}\text { Applications per student } \\
\text { Applications per student who applied to Berkeley or UCLA } \\
\text { Percent of applications sent to schools ranked 1-10 } \\
\text { Percent of applications sent to schools ranked 11-20 } \\
\text { Percent of students who applied to Berkeley } \\
\text { Percent of students who applied to UCLA }\end{array}$} & $\begin{array}{l}5.7 \\
7.8 \\
59 \% \\
20 \% \\
28 \% \\
14 \%\end{array}$ \\
\hline \multicolumn{4}{|c|}{ B. Applications and Students in the 17-School EALS Sample Used in the Paper } \\
\hline \multicolumn{3}{|c|}{$\begin{array}{l}\text { Applications } \\
\text { Students } \\
\text { Applications and applicants to Berkeley (7th-most in the 17-school sample) } \\
\text { Applications and applicants to UCLA (13th-most in the 17-school sample) }\end{array}$} & $\begin{array}{l}25,499 \\
5,353 \\
1,594 \\
777\end{array}$ \\
\hline \multicolumn{4}{|c|}{ C. Mean Student Characteristics in the 17-School EALS Sample Used in the Paper and Nationwide } \\
\hline \multicolumn{3}{|c|}{$\begin{array}{c}\text { EALS } \\
(\mathrm{sd})\end{array}$} & \\
\hline LSAT & $\begin{array}{l}166.2 \\
(6.7)\end{array}$ & 151.5 & \\
\hline GPA & $\begin{array}{c}3.43 \\
(0.33)\end{array}$ & 3.16 & \\
\hline $\begin{array}{l}\text { White } \\
\text { Asian } \\
\text { Black } \\
\text { Hispanic }\end{array}$ & $\begin{array}{l}60.8 \% \\
19.4 \% \\
9.7 \% \\
10.1 \%\end{array}$ & $\begin{array}{c}70.9 \% \\
7.7 \% \\
12.4 \% \\
9.1 \%\end{array}$ & \\
\hline Post-ban & $54.8 \%$ & & \\
\hline
\end{tabular}

Notes - Panel A lists statistics on the application behavior of EALS students, using all complete observations (32,627 applications from 5,692 students applying to law schools nationwide). The rankings refer to the rankings from the 1998 issue of U.S. News and World Report's "America's Best Graduate Schools". Panel B lists statistics on applications submitted to the seventeen law schools used in the paper; see the notes to Table 1 for details. Panel C lists mean applicant characteristics. The Nationwide column lists statistics for all U.S. law school applicants in application year 2000-2001, the closest available year to the midpoint of the EALS sample. LSAT is the standardized test score used in law school admissions and ranges from 120 to 180 . Undergraduate grade point average is the cumulative undergraduate GPA on a 4.00 scale. The Hispanic category includes students classified as Hispanic, Chicano/Mexican-American, or Puerto Rican. Post-ban is an indicator for the student applying to law school in application year 1996-1997 or later. The 5.4\% of EALS students who either do not report race or list their race as American Indian/Alaskan Native, Canadian Aboriginal, or Other are omitted from EALS statistics in this table and all analyses; the corresponding $7.9 \%$ of U.S. applicants are omitted from the nationwide percentages as well. The nationwide data were collected from various tables at http://www.lsac.org/LSACResources/default.asp. 
ONLINE APPENDIX TABLE 2

Effect on Selection-Corrected Black Admission Rates

Semi-Parametric Estimates

\begin{tabular}{|c|c|c|c|c|}
\hline \multicolumn{4}{|c|}{ Admission Rates at Non-UC Schools } & \\
\hline & Pre-ban & Post-ban & Difference (pp) & \\
\hline White & $40.6 \%$ & $46.1 \%$ & 5.5 & \\
\hline Black & $61.2 \%$ & $63.0 \%$ & 1.9 & \\
\hline Difference (pp) & 20.6 & 16.9 & -3.6 & \\
\hline \multicolumn{5}{|c|}{ Admission Rates at Berkeley } \\
\hline & Pre-ban & Post-ban & Difference (pp) & \\
\hline White & $31.0 \%$ & $33.9 \%$ & 2.9 & \\
\hline Black & $56.7 \%$ & $26.0 \%$ & -30.6 & \\
\hline Difference (pp) & 25.7 & -7.9 & -33.6 & \\
\hline \multicolumn{4}{|c|}{ DDD estimate (percentage points): } & -29.9 \\
\hline \multicolumn{4}{|c|}{ DDD estimate, as $\%$ of pre-ban black admission rate: } & $-52.8 \%$ \\
\hline \multicolumn{4}{|c|}{ Admission Rates at UCLA } & \\
\hline & Pre-ban & Post-ban & Difference (pp) & \\
\hline$\overline{\text { White }}$ & $48.0 \%$ & $60.1 \%$ & 12.2 & \\
\hline Black & $64.5 \%$ & $32.4 \%$ & -32.1 & \\
\hline Difference (pp) & 16.6 & -27.7 & -44.3 & \\
\hline \multicolumn{4}{|c|}{ DDD estimate (percentage points): } & -40.7 \\
\hline \multicolumn{4}{|c|}{ DDD estimate, as $\%$ of pre-ban black admission rate: } & $-63.0 \%$ \\
\hline
\end{tabular}

Notes - This table constructs the semi-parametric triple-difference (DDD) estimates of the change in black admission rates at Berkeley and UCLA reported in Figure 3. Each pre-ban admission rate is an actual admission rate. Each post-ban admission rate is a reweighted estimate of the admission rate that pre-ban applicants of each race and school are predicted to have experienced after the ban; see Section IV.B for the reweighting procedure. The differences computed in the DDD are between pre-ban and post-ban periods, UC and non-UC schools, and black and white races. The non-UC schools are the top-fifteen schools in the EALS that were never subject to an affirmative action ban. See Table 2 for analogous parametric DDD estimates that account for the fact that a decline in black admission rates opens up space in the admitted cohort for members of both races. 
ONLINE APPENDIX TABLE 3

Effect on Selection-Corrected Black Admission Rates

\begin{tabular}{|c|c|c|c|c|c|c|c|}
\hline \multirow[t]{3}{*}{ Dependent Variable: } & \multicolumn{7}{|c|}{ Admitted } \\
\hline & \multicolumn{2}{|c|}{ OLS } & \multicolumn{5}{|c|}{$\begin{array}{c}\text { Probit } \\
\text { (average marginal effect) }\end{array}$} \\
\hline & $\begin{array}{l}\text { (pp) } \\
(1)\end{array}$ & $\begin{array}{l}\text { (pp) } \\
(2)\end{array}$ & $\begin{array}{l}\text { (pp) } \\
(3)\end{array}$ & $\begin{array}{l}(\mathrm{pp}) \\
(4)\end{array}$ & $\begin{array}{c}(\mathrm{pp}) \\
(5)\end{array}$ & $\begin{array}{l}\text { (pp) } \\
(6)\end{array}$ & $\begin{array}{l}\text { (pp) } \\
(7)\end{array}$ \\
\hline \multicolumn{8}{|l|}{ A. Berkeley } \\
\hline Black $\times$ Post-ban & $\begin{array}{l}-39.7 \\
(6.8)\end{array}$ & $\begin{array}{l}-31.8 \\
(7.3)\end{array}$ & $\begin{array}{l}-40.5 \\
(5.4)\end{array}$ & $\begin{array}{l}-35.5 \\
(6.3)\end{array}$ & $\begin{array}{l}-40.0 \\
(5.3)\end{array}$ & $\begin{array}{l}-33.9 \\
(6.5)\end{array}$ & $\begin{array}{l}-43.6 \\
(5.5)\end{array}$ \\
\hline $\begin{array}{l}\text { National trend controls } \\
\text { Inferred strength control } \\
\text { CA residency control }\end{array}$ & & $x$ & & $x$ & $x$ & $\begin{array}{l}X \\
X\end{array}$ & $\begin{array}{l}x \\
x\end{array}$ \\
\hline $\begin{array}{l}\text { N (applications) } \\
\text { Clusters (applicants) }\end{array}$ & $\begin{array}{l}1,029 \\
1,029\end{array}$ & $\begin{array}{c}17,329 \\
3,754\end{array}$ & $\begin{array}{l}1,029 \\
1,029\end{array}$ & $\begin{array}{l}17,329 \\
3,754\end{array}$ & $\begin{array}{l}1,029 \\
1,029\end{array}$ & $\begin{array}{c}17,329 \\
3,754\end{array}$ & $\begin{array}{l}779 \\
779\end{array}$ \\
\hline $\begin{array}{l}\text { Actual pre-ban black admission rate } \\
\Delta \text { implied by Black } \times \text { Post-ban effect }\end{array}$ & $\begin{array}{l}56.7 \\
-34.2\end{array}$ & $\begin{array}{l}56.7 \\
-27.4\end{array}$ & $\begin{array}{l}56.7 \\
-35.7\end{array}$ & $\begin{array}{l}56.7 \\
-31.1\end{array}$ & $\begin{array}{l}56.7 \\
-35.6\end{array}$ & $\begin{array}{l}56.7 \\
-30.0\end{array}$ & $\begin{array}{r}56.7 \\
-39.7\end{array}$ \\
\hline \multicolumn{8}{|l|}{ B. UCLA } \\
\hline Black $\times$ Post-ban & $\begin{array}{l}-48.1 \\
(10.5)\end{array}$ & $\begin{array}{l}-41.6 \\
(10.4)\end{array}$ & $\begin{array}{l}-35.3 \\
(11.1)\end{array}$ & $\begin{array}{l}-32.8 \\
(11.0)\end{array}$ & $\begin{array}{l}-35.0 \\
(11.2)\end{array}$ & $\begin{array}{l}-33.5 \\
(11.1)\end{array}$ & $\begin{array}{l}-31.1 \\
(10.5)\end{array}$ \\
\hline $\begin{array}{l}\text { National trend controls } \\
\text { Inferred strength control } \\
\text { CA residency control }\end{array}$ & & $x$ & & $x$ & $x$ & $\begin{array}{l}x \\
X\end{array}$ & $\begin{array}{l}x \\
X\end{array}$ \\
\hline $\begin{array}{l}\text { N (applications) } \\
\text { Clusters (applicants) }\end{array}$ & $\begin{array}{l}485 \\
485\end{array}$ & $\begin{array}{c}16,785 \\
3,736\end{array}$ & $\begin{array}{l}485 \\
485\end{array}$ & $\begin{array}{l}16,785 \\
3,736\end{array}$ & $\begin{array}{l}485 \\
485\end{array}$ & $\begin{array}{c}16,785 \\
3,736\end{array}$ & $\begin{array}{l}371 \\
371\end{array}$ \\
\hline $\begin{array}{l}\text { Actual pre-ban black admission rate } \\
\Delta \text { implied by Black } \times \text { Post-ban effect }\end{array}$ & $\begin{array}{r}64.5 \\
-41.6\end{array}$ & $\begin{array}{r}64.5 \\
-35.9\end{array}$ & $\begin{array}{l}64.5 \\
-32.1\end{array}$ & $\begin{array}{r}64.5 \\
-29.2\end{array}$ & $\begin{array}{r}64.5 \\
-32.0\end{array}$ & $\begin{array}{r}64.5 \\
-30.2\end{array}$ & $\begin{array}{r}64.5 \\
-29.2\end{array}$ \\
\hline
\end{tabular}

$\overline{\text { Notes - This table replicates columns 6-9 from Table 2, including two additional columns that use ordinary least squares }}$ rather than probit estimation. 
ONLINE APPENDIX TABLE 4

Effect on Selection-Corrected Black Admission Rates

Using Applications from All Races

\begin{tabular}{|c|c|c|c|c|c|c|c|}
\hline \multirow[t]{3}{*}{ Dependent Variable: } & \multicolumn{7}{|c|}{ Admitted } \\
\hline & \multicolumn{2}{|c|}{ OLS } & \multicolumn{5}{|c|}{$\begin{array}{c}\text { Probit } \\
\text { (average marginal effect) }\end{array}$} \\
\hline & $\begin{array}{c}(\mathrm{pp}) \\
(1) \\
\end{array}$ & $\begin{array}{c}(\mathrm{pp}) \\
(2)\end{array}$ & $\begin{array}{l}\text { (pp) } \\
(3)\end{array}$ & $\begin{array}{c}(\mathrm{pp}) \\
(4)\end{array}$ & $\begin{array}{c}\text { (pp) } \\
(5)\end{array}$ & $\begin{array}{c}(\mathrm{pp}) \\
(6)\end{array}$ & $\begin{array}{l}(\mathrm{pp}) \\
(7)\end{array}$ \\
\hline \multicolumn{8}{|l|}{ A. Berkeley } \\
\hline Black $\times$ Post-ban & $\begin{array}{l}-38.1 \\
(6.9)\end{array}$ & $\begin{array}{l}-30.8 \\
(7.3)\end{array}$ & $\begin{array}{l}-39.8 \\
(5.6)\end{array}$ & $\begin{array}{l}-34.8 \\
(6.4)\end{array}$ & $\begin{array}{l}-38.6 \\
(5.5)\end{array}$ & $\begin{array}{l}-32.7 \\
(6.7)\end{array}$ & $\begin{array}{r}-42.5 \\
(5.8)\end{array}$ \\
\hline $\begin{array}{l}\text { National trend controls } \\
\text { Inferred strength control } \\
\text { CA residency control }\end{array}$ & & $x$ & & $x$ & $x$ & $\begin{array}{l}x \\
x\end{array}$ & $\begin{array}{l}X \\
X\end{array}$ \\
\hline $\begin{array}{l}\text { N (applications) } \\
\text { Clusters (applicants) }\end{array}$ & $\begin{array}{l}1,594 \\
1,594\end{array}$ & $\begin{array}{c}24,722 \\
5,324\end{array}$ & $\begin{array}{l}1,594 \\
1,594\end{array}$ & $\begin{array}{c}24,722 \\
5,324\end{array}$ & $\begin{array}{l}1,594 \\
1,594\end{array}$ & $\begin{array}{l}24,722 \\
5,324\end{array}$ & $\begin{array}{l}1,197 \\
1,197\end{array}$ \\
\hline $\begin{array}{l}\text { Actual pre-ban black admission rate } \\
\triangle \text { implied by Black } \times \text { Post-ban effect } \\
\text { B. UCLA }\end{array}$ & $\begin{array}{r}56.7 \\
-34.6\end{array}$ & $\begin{array}{l}56.7 \\
-28.0\end{array}$ & $\begin{array}{l}56.7 \\
-36.5\end{array}$ & $\begin{array}{l}56.7 \\
-31.7\end{array}$ & $\begin{array}{l}56.7 \\
-36.0\end{array}$ & $\begin{array}{l}56.7 \\
-30.3\end{array}$ & $\begin{array}{l}56.7 \\
-40.1\end{array}$ \\
\hline Black $\times$ Post-ban & $\begin{array}{l}-45.4 \\
(10.4)\end{array}$ & $\begin{array}{l}-39.0 \\
(10.5)\end{array}$ & $\begin{array}{l}-35.9 \\
(10.3)\end{array}$ & $\begin{array}{l}-32.1 \\
(10.8)\end{array}$ & $\begin{array}{l}-35.1 \\
(10.3)\end{array}$ & $\begin{array}{l}-32.0 \\
(10.8)\end{array}$ & $\begin{array}{l}-33.2 \\
(10.2)\end{array}$ \\
\hline $\begin{array}{l}\text { National trend controls } \\
\text { Inferred strength control } \\
\text { CA residency control }\end{array}$ & & $x$ & & $x$ & $x$ & $\begin{array}{l}X \\
X\end{array}$ & $\begin{array}{l}x \\
x\end{array}$ \\
\hline $\begin{array}{l}\text { N (applications) } \\
\text { Clusters (applicants) }\end{array}$ & $\begin{array}{l}777 \\
777\end{array}$ & $\begin{array}{c}23,905 \\
5,300\end{array}$ & $\begin{array}{l}777 \\
777\end{array}$ & $\begin{array}{c}23,905 \\
5,300\end{array}$ & $\begin{array}{l}777 \\
777\end{array}$ & $\begin{array}{c}23,905 \\
5,300\end{array}$ & $\begin{array}{l}586 \\
586\end{array}$ \\
\hline $\begin{array}{l}\text { Actual pre-ban black admission rate } \\
\Delta \text { implied by Black } \times \text { Post-ban effect }\end{array}$ & $\begin{array}{r}64.5 \\
-41.4\end{array}$ & $\begin{array}{r}64.5 \\
-35.5\end{array}$ & $\begin{array}{r}64.5 \\
-34.6\end{array}$ & $\begin{array}{r}64.5 \\
-30.4\end{array}$ & $\begin{array}{r}64.5 \\
-34.6\end{array}$ & $\begin{array}{r}64.5 \\
-30.9\end{array}$ & $\begin{array}{r}64.5 \\
-33.0\end{array}$ \\
\hline
\end{tabular}

Notes - This table replicates Appendix Table 3 using applications from all races (black, white, Asian, and Hispanic). The regressions underlying this table are the same as those underlying Table 2 except that the black indicator is replaced by a vector of black, Asian, and Hispanic indicators. 
ONLINE APPENDIX TABLE 5

Effect on Selection-Corrected Black Admission Rates

Using Applications from All Races and Controlling for Full Interactions

\begin{tabular}{|c|c|c|c|c|c|c|c|}
\hline \multirow[t]{3}{*}{ Dependent Variable: } & \multicolumn{7}{|c|}{ Admitted } \\
\hline & \multicolumn{2}{|c|}{ OLS } & \multicolumn{5}{|c|}{$\begin{array}{c}\text { Probit } \\
\text { (average marginal effect) }\end{array}$} \\
\hline & $\begin{array}{c}\text { (pp) } \\
(1)\end{array}$ & $\begin{array}{l}\text { (pp) } \\
(2)\end{array}$ & $\begin{array}{l}\text { (pp) } \\
(3)\end{array}$ & $\begin{array}{l}(\mathrm{pp}) \\
(4)\end{array}$ & $\begin{array}{c}(\mathrm{pp}) \\
(5)\end{array}$ & $\begin{array}{l}\text { (pp) } \\
(6)\end{array}$ & $\begin{array}{l}\text { (pp) } \\
(7)\end{array}$ \\
\hline \multicolumn{8}{|l|}{ A. Berkeley } \\
\hline Black $\times$ Post-ban & $\begin{array}{l}-47.3 \\
(7.1)\end{array}$ & $\begin{array}{l}-40.6 \\
(7.4)\end{array}$ & $\begin{array}{l}-47.2 \\
(4.8)\end{array}$ & $\begin{array}{l}-46.0 \\
(5.3)\end{array}$ & $\begin{array}{l}-49.1 \\
(4.6)\end{array}$ & $\begin{array}{l}-47.7 \\
(5.1)\end{array}$ & $\begin{array}{l}-50.3 \\
(4.7)\end{array}$ \\
\hline $\begin{array}{l}\text { National trend controls } \\
\text { Inferred strength control } \\
\text { CA residency control }\end{array}$ & & $x$ & & $x$ & $x$ & $\begin{array}{l}x \\
x\end{array}$ & $\begin{array}{l}X \\
X\end{array}$ \\
\hline $\begin{array}{l}\text { N (applications) } \\
\text { Clusters (applicants) }\end{array}$ & $\begin{array}{l}1,594 \\
1,594\end{array}$ & $\begin{array}{c}24,722 \\
5,324\end{array}$ & $\begin{array}{l}1,594 \\
1,594\end{array}$ & $\begin{array}{c}24,722 \\
5,324\end{array}$ & $\begin{array}{l}1,588 \\
1,588\end{array}$ & $\begin{array}{c}24,716 \\
5,318\end{array}$ & $\begin{array}{l}1,192 \\
1,192\end{array}$ \\
\hline $\begin{array}{l}\text { Actual pre-ban black admission rate } \\
\triangle \text { implied by Black } \times \text { Post-ban effect } \\
\text { B. UCLA }\end{array}$ & $\begin{array}{l}56.7 \\
-42.9\end{array}$ & $\begin{array}{l}56.7 \\
-36.9\end{array}$ & $\begin{array}{l}56.7 \\
-44.2\end{array}$ & $\begin{array}{l}56.7 \\
-42.9\end{array}$ & $\begin{array}{r}56.7 \\
-44.5\end{array}$ & $\begin{array}{l}56.7 \\
-43.0\end{array}$ & $\begin{array}{r}56.7 \\
-45.6\end{array}$ \\
\hline Black $\times$ Post-ban & $\begin{array}{l}-46.0 \\
(10.8)\end{array}$ & $\begin{array}{l}-38.0 \\
(10.8)\end{array}$ & $\begin{array}{l}-44.9 \\
(8.9)\end{array}$ & $\begin{array}{l}-41.8 \\
(9.7)\end{array}$ & $\begin{array}{l}-44.7 \\
(8.7)\end{array}$ & $\begin{array}{l}-41.3 \\
(9.8)\end{array}$ & $\begin{array}{r}-46.4 \\
(7.7)\end{array}$ \\
\hline $\begin{array}{l}\text { National trend controls } \\
\text { Inferred strength control } \\
\text { CA residency control }\end{array}$ & & $x$ & & $x$ & $x$ & $\begin{array}{l}X \\
X\end{array}$ & $\begin{array}{l}x \\
X\end{array}$ \\
\hline $\begin{array}{l}\text { N (applications) } \\
\text { Clusters (applicants) }\end{array}$ & $\begin{array}{l}777 \\
777\end{array}$ & $\begin{array}{c}23,905 \\
5,300\end{array}$ & $\begin{array}{l}777 \\
777\end{array}$ & $\begin{array}{c}23,905 \\
5,300\end{array}$ & $\begin{array}{l}777 \\
777\end{array}$ & $\begin{array}{c}23,905 \\
5,300\end{array}$ & $\begin{array}{l}586 \\
586\end{array}$ \\
\hline $\begin{array}{l}\text { Actual pre-ban black admission rate } \\
\Delta \text { implied by Black } \times \text { Post-ban effect }\end{array}$ & $\begin{array}{r}64.5 \\
-41.9\end{array}$ & $\begin{array}{r}64.5 \\
-34.6\end{array}$ & $\begin{array}{l}64.5 \\
-42.1\end{array}$ & $\begin{array}{r}64.5 \\
-38.9\end{array}$ & $\begin{array}{l}64.5 \\
-42.4\end{array}$ & $\begin{array}{r}64.5 \\
-38.8\end{array}$ & $\begin{array}{l}64.5 \\
-45.1\end{array}$ \\
\hline
\end{tabular}

Notes - This table replicates Appendix Table 3 using applications from all races (black, white, Asian, and Hispanic) and more interactions. The regressions underlying this table are the same as those underlying Table 2 except for two changes. First, the black indicator is replaced by a vector of black, Asian, and Hispanic indicators. Second, each non-racial covariate (LSAT, GPA, inferred strength, and California residency, depending on the specification) is interacted with each of the DD or DDD variables (the vector of race indicators, the post-ban indicator, the UC-school indicator, and any interactions of these variables). For example, column 1 regresses admission on LSAT, GPA, race indicators, year fixed effects, the race indicators interacted with the post-ban indicator, LSAT interacted with the post-ban indicator, GPA interacted with the postban indicator, LSAT interacted with the race indicators, and GPA interacted with the race indicators. 
FIGURE 1

Berkeley Admission Rates and Racial Mix of Applicants

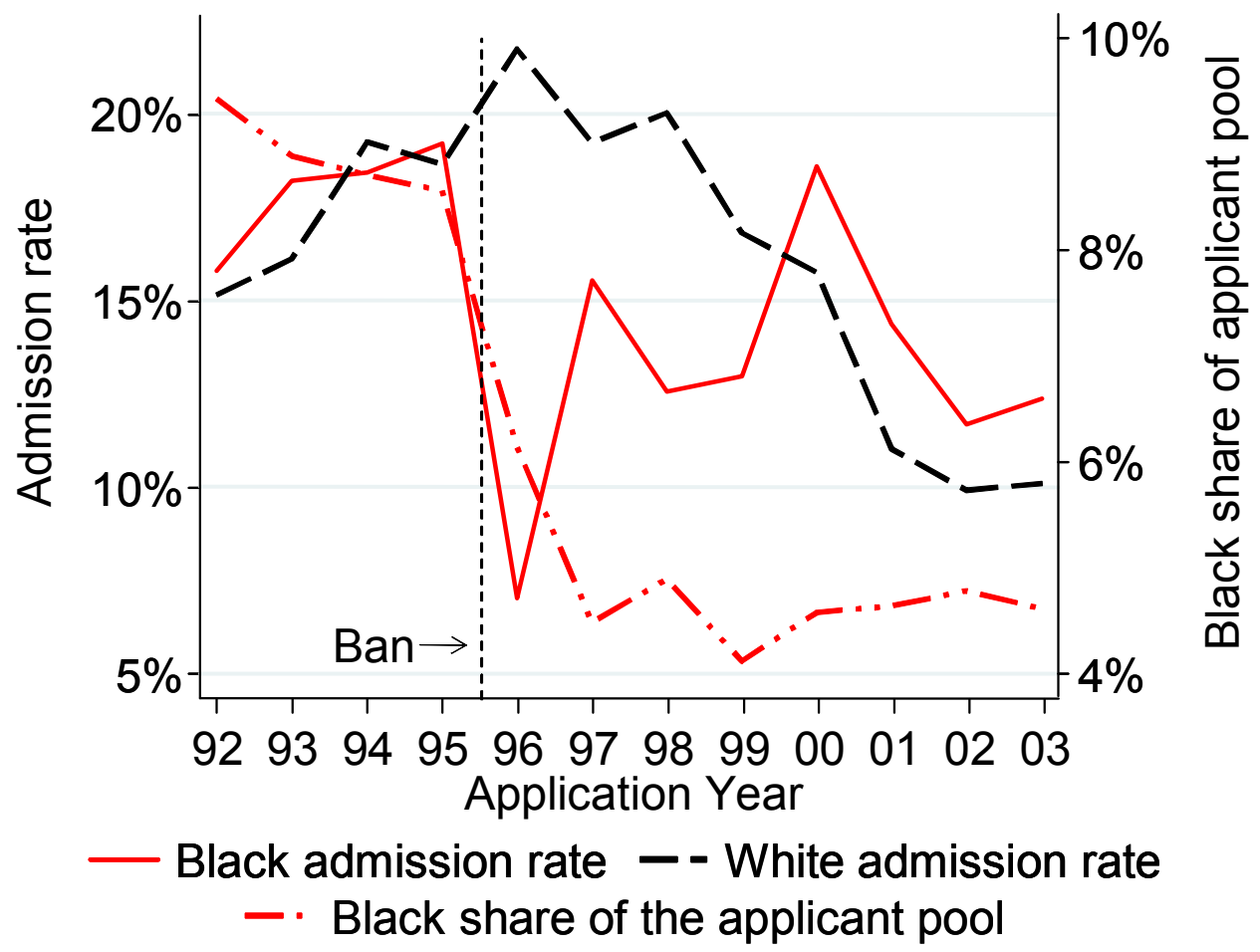

Notes - This graph uses public aggregates on the universe of applicants to Berkeley to plot the time series of overall admission rates by race and the black share of the applicant pool at Berkeley for all available years. Application year refers to the autumn of the application year. Averaged across 1992-1995 and 2000-2003, the black-minus-white admission rate differential rose from 0.6 to 2.6 percentage points, and the black share of the applicant pool declined from $8.9 \%$ to $4.7 \%$. Yield rates (the share of admitted students who enrolled, not plotted here) changed comparably for blacks and whites: $29.2 \%$ to $32.9 \%$ for blacks and $30.4 \%$ to $33.1 \%$ for whites. The share of first-year enrollees who were black (not plotted here but implied by these preceding statistics) declined from $8.7 \%$ to $5.2 \%$. These school-year-race aggregates contain no information on applicant credentials. See Online Appendix Figure 1 for the analogous graph for UCLA. The underlying data are no longer posted on the website of the UC Office of the President but are available on the author's website. 


\section{FIGURE 2}

\section{Race, Academic Credentials, and Admission under Affirmative Action}

(a) Scatterplot of 23,128 Admission Decisions at Non-UC Schools ( $5 \%$ Random Sample)

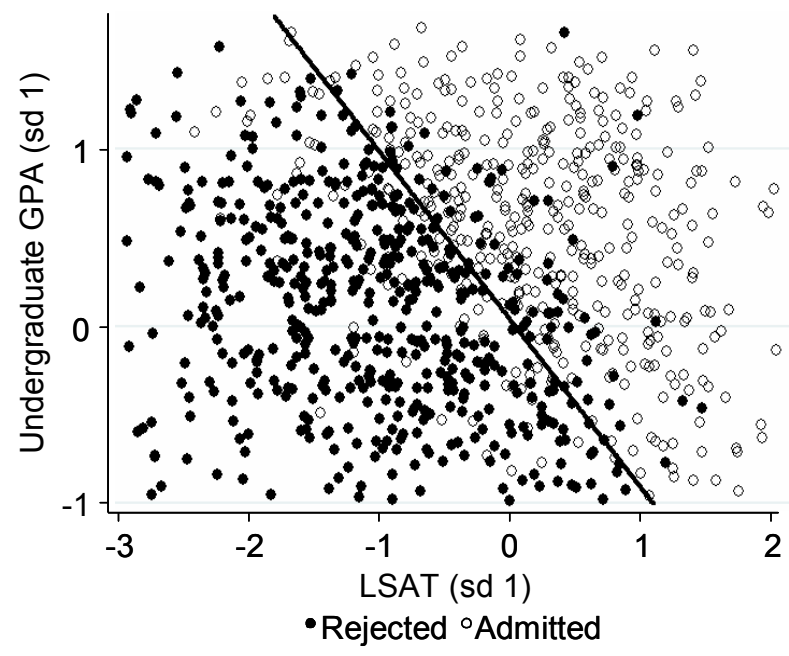

(b) Characterizing Admission Rules

Using Academic Strength (LSAT+GPA)

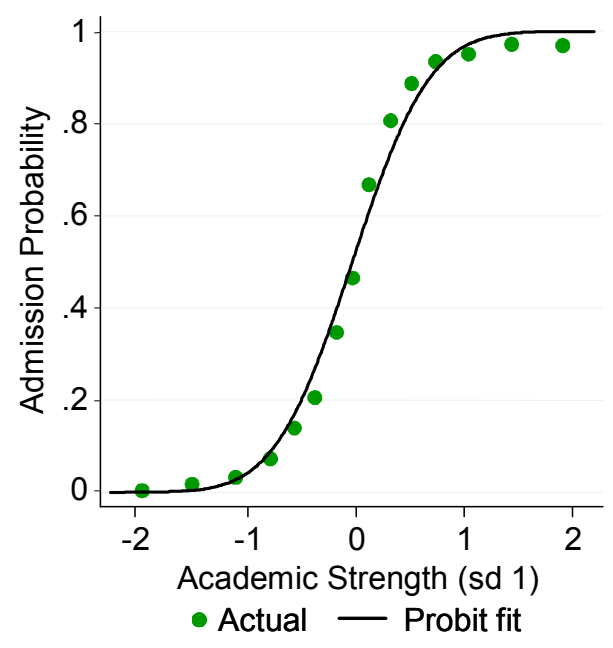

(c) Pre-ban UC Admission Rules in Academic Strength

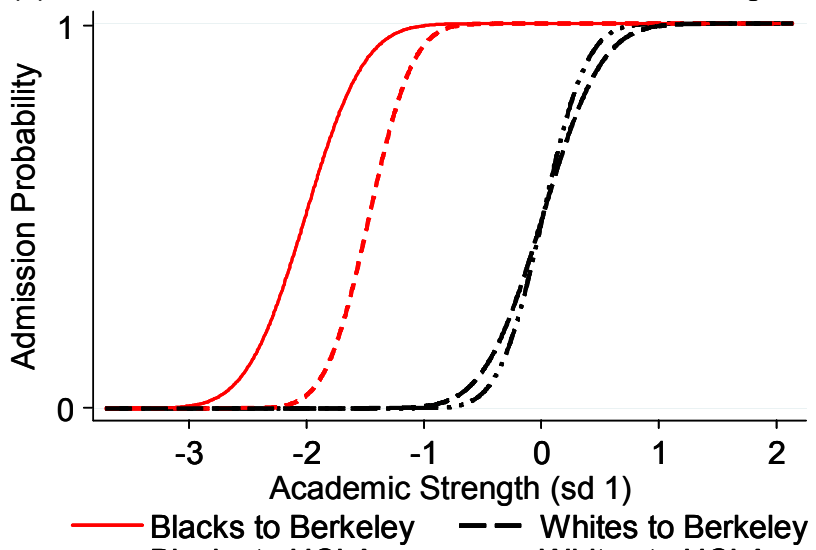

- - - Blacks to UCLA - -.. Whites to UCLA

Notes - Panel A plots standardized LSAT score (mean zero and standard deviation one), standardized undergraduate GPA, and the actual admission decision for a 5\% random sample of the 23,128 Elite Applications to Law School (EALS) applications submitted to the top-fifteen non-UC schools that were never subject to an affirmative action ban. Online Appendix Figure 4 displays the full sample in color. To account for cross-school selectivity differences, each application's LSAT has been additively shifted by its school-year-race fixed effect from a probit regression of admission on LSAT, GPA, and these fixed effects (see Section III.C); the overlaid best-fit admission threshold line correctly predicts $89.1 \%$ of admissions decisions. The regression indicates that a one standard deviation higher LSAT is about as valuable in the admissions cross section as a one standard deviation higher GPA. Thus when useful for Figure 3, I summarize an application's LSAT and GPA with the scalar index academic strength, equal to the standardized sum of standardized LSAT and standardized GPA. Panel B plots admission rates within fifteen academic strength bins using all 23,128 non-UC applications and overlays the univariate probit fit, where each application's academic strength has been additively shifted by its school-year-race fixed effect from a probit regression of admission on academic strength and these fixed effects. Panel C plots probit-fitted admission rules by race at UC schools before the 1996 affirmative action ban, derived from a regression of admission on academic strength, a black indicator, and year fixed effects using pre-ban black and white applications to Berkeley, and separately for UCLA. For ease of comparison, each school's pair of admission rules has been horizontally shifted by an additive constant so that the predicted admission probability for whites equals 0.5 at academic strength 0 . 
FIGURE 3

\section{Selection-Corrected Admission Rates by Race}
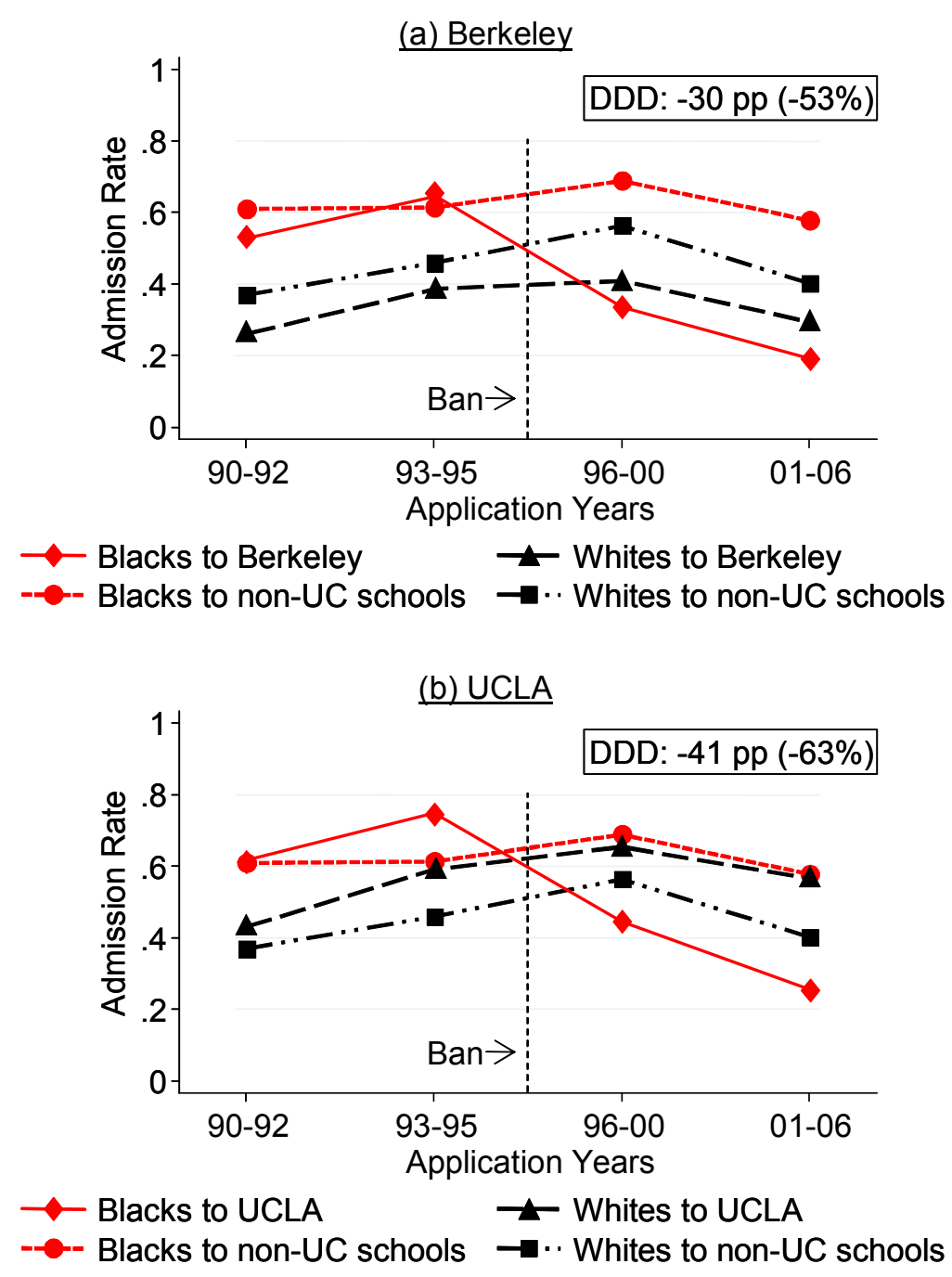

Notes - This figure displays the time series of black and white admission rates at Berkeley, UCLA, and non-UC schools, where applicant characteristics have been held constant at pre-ban levels using semi-parametric reweighting as in DiNardo, Fortin, and Lemieux (1996). To construct the time series of black admission rates at Berkeley, I first compute terciles of academic strength among pre-ban black applications to Berkeley. Then for each time period shown in the figure, I weight black applications to Berkeley so that each pre-ban-defined tercile receives equal weight when computing the displayed admission rate. I repeat this process for whites at Berkeley and for whites and blacks separately at UCLA and at each non-UC school, averaging across non-UC schools to construct the non-UC series. This semi-parametric reweighting on academic strength is data-demanding, so I group the data into two pre-ban time periods (1990-1992 and 1993-1995) and two post-ban time periods (1996-2000 and 2001-2006). Pooling all pre-ban years and all post-ban years, the triple-difference (DDD) estimate of the effect of the ban on the black admission rate at each UC school is overlaid, with the DDD estimate as a fraction of the pre-ban black admission rate in parentheses. Online Appendix Table 2 lists the numbers underlying these DDD estimates. Table 2 reports parametric DDD estimates that account for the minor space-opening effect of a decline in black admission rates. 

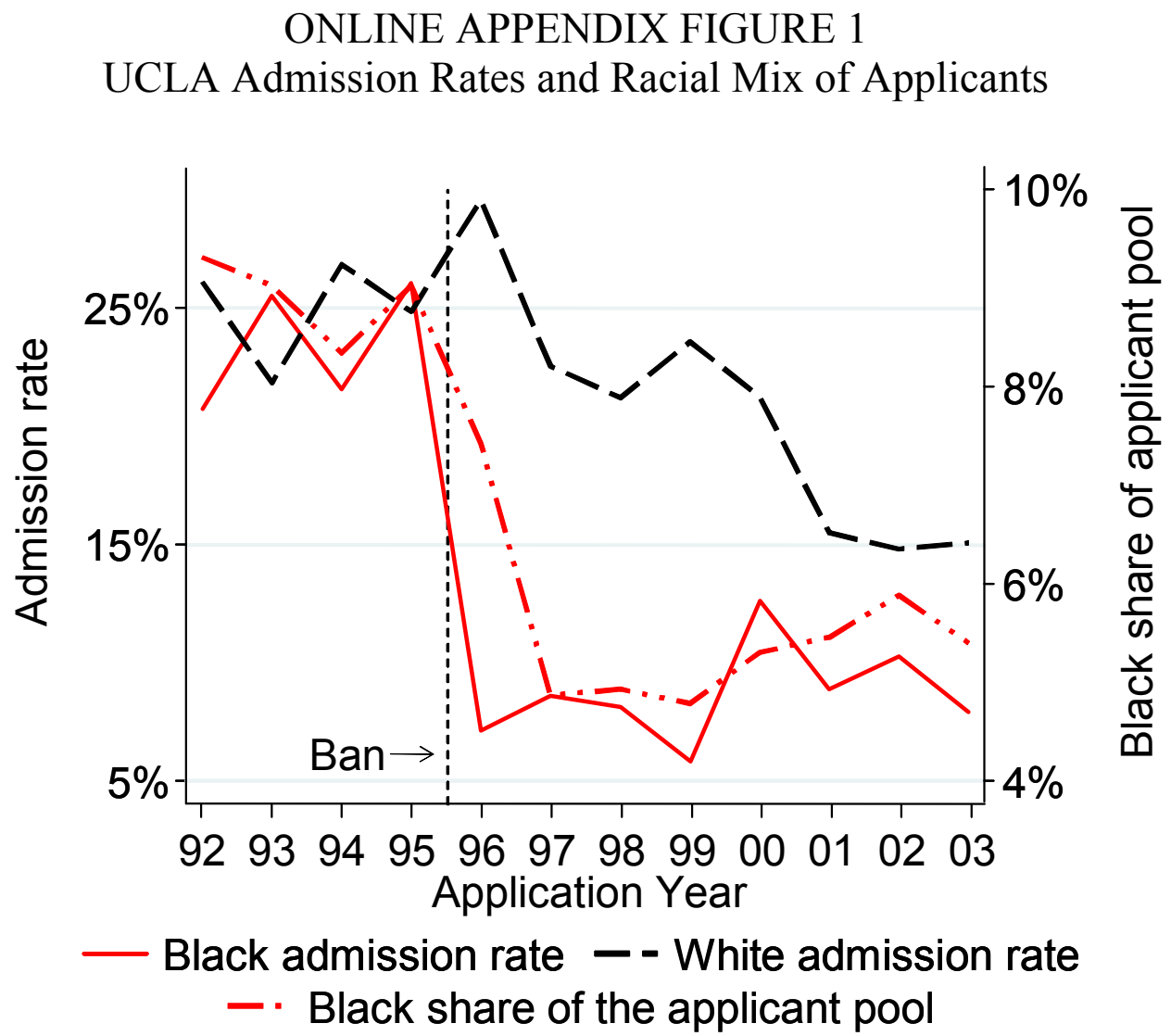

Notes - This graph replicates Figure 1 for UCLA; see the notes to that figure for details. Averaged across 1992-1995 and 2000-2003, the black-minus-white admission rate differential fell from -1.4 to 6.7 percentage points, and the black share of the applicant pool declined from $8.9 \%$ to $5.5 \%$. Yield rates (the share of admitted students who enrolled, not plotted here) rose somewhat among blacks relative to whites: $25.4 \%$ to $37.1 \%$ for blacks and $26.6 \%$ to $30.9 \%$ for whites. The share of first-year enrollees who were black (not plotted here but implied by these preceding statistics) declined from $8.3 \%$ to $4.3 \%$. 


\section{ONLINE APPENDIX FIGURE 2 Personal Statement Prompts on Berkeley Application Forms}

\section{(a) 1995, the last pre-ban year}

\section{Personal Statement}

The required personal statement is your opportunity to submit information you would like the reader of your file to have when evaluating your application. A résumé or chronological list of activities may accompany the personal statement.

The content of the statement is up to you; we would appreciate your limiting its length to about two typewritten pages. Be sure to include your social security number and sign your statement. You may wish to address the admissions criteria described in the paragraphs above as well as the following:

- Academic honors, awards or other recognition you have received not based solely on grade average;

- Influences on your life such as cultural, ethnic, or racial background or your circumstances while growing up;

- Physical or learning disabilities and any effect they may have had on your admissions credentials. Special resources and services are available to students with disabilities. Please contact the Disabled Students' Program, (510) 642-0518, for further information. (See page 45, Applicants with Disabilities.)

- Extracurricular, community, or other activities in the order of their importance to you;

- Work experience including nature and amount of outside employment while in college;

- For college graduates, the nature of your activities or employment since graduation;

- Description of your graduate studies, if any;

- Other test scores you would like to report (SAT, GRE, etc.);

- College grading and course selection, and college grade trends;

- Any additional information that would indicate that your admission would add diversity to the entering class.

\section{(b) 1996, the first post-ban year}

\section{Personal Statement}

Please submit a statement providing more information about yourself. The subject matter of the essay is up to you, but keep in mind that the reader will be seeking to get a sense of you as a person and as a potential student and graduate of Boalt Hall.

As stated in the Faculty Policy Governing Admission, Boalt Hall seeks to enroll a class with varied backgrounds and interests. Such diversity contributes to the learning environment of the law school and historically has produced graduates who have served all segments of society and who have become leaders in many fields of law. If you wish, you may separately discuss how your interests, background, life experiences and perspectives would contribute to the diversity of the entering class. If applicable, you may also describe any disadvantages that may have adversely affected your past performance, including such disadvantages as language barriers, or a personal or family history of educational or socioeconomic disadvantage.

Notes - This figure reprints the personal statement prompts from the 1995 (the autumn of the last pre-ban application year) and the 1996 (the autumn of the first post-ban application year) Berkeley application forms. The 1995 personal statement prompt was nearly identical to the one from 1994, and the personal statement prompt has remained nearly unchanged since 1996. 
ONLINE APPENDIX FIGURE 3

\section{Distribution of Academic Credentials By Race}

(a) Distribution of LSAT Score

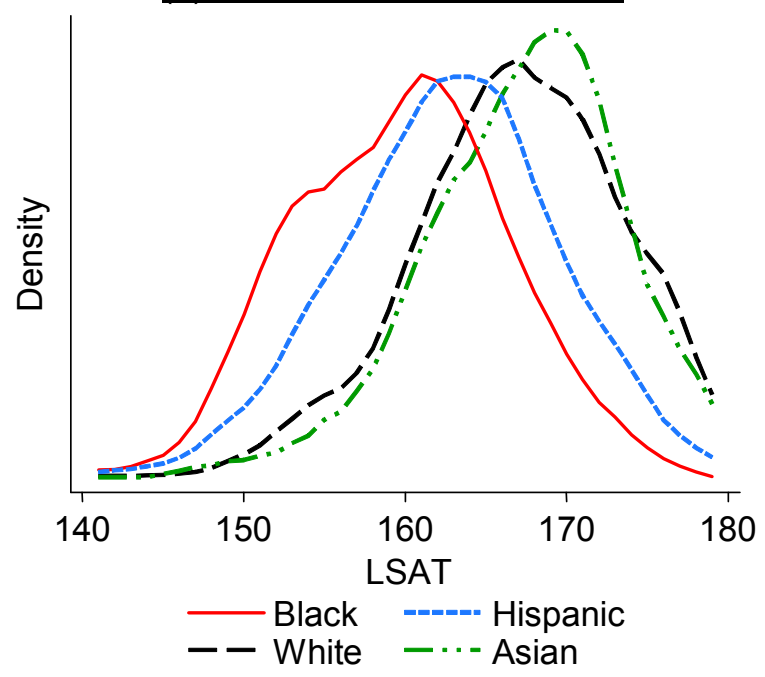

(c) Distribution of Academic Strength

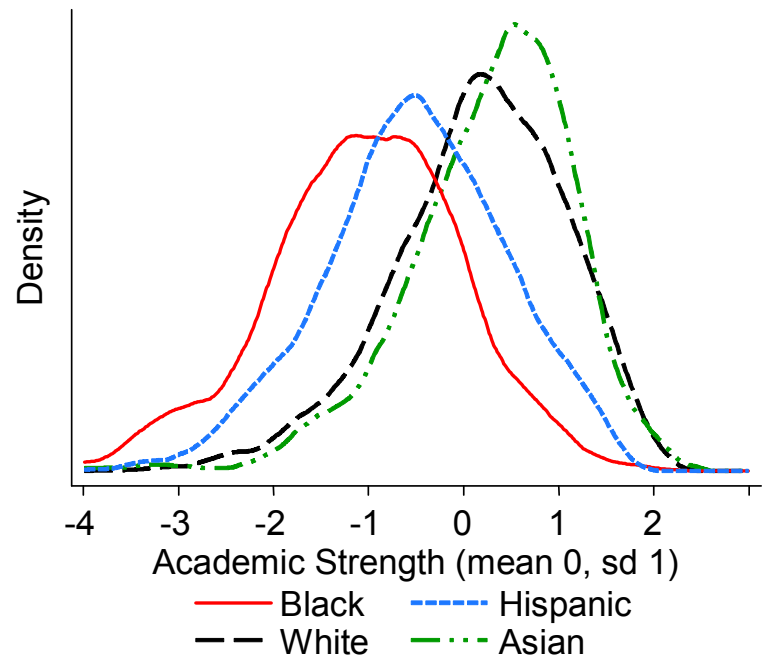

(b) Distribution of Undergraduate GPA

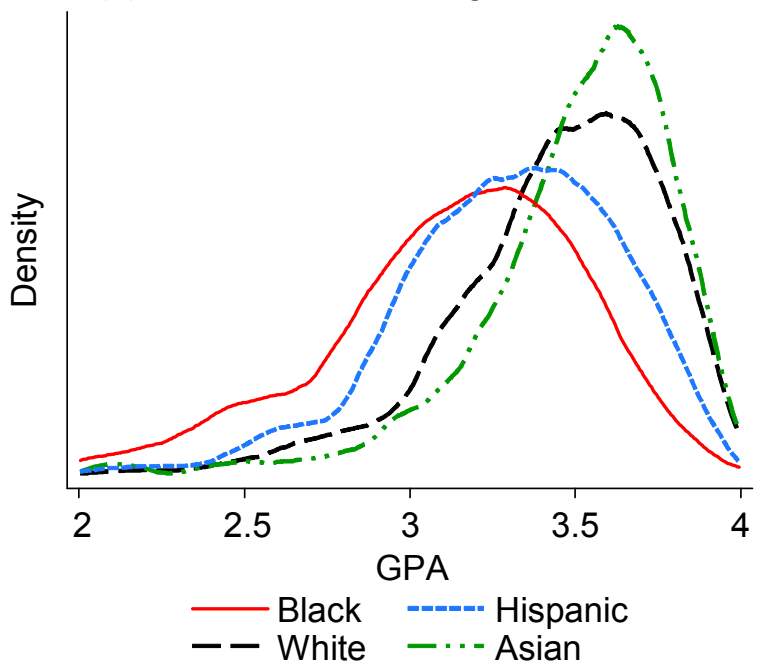

(d) Time Series of Academic Strength

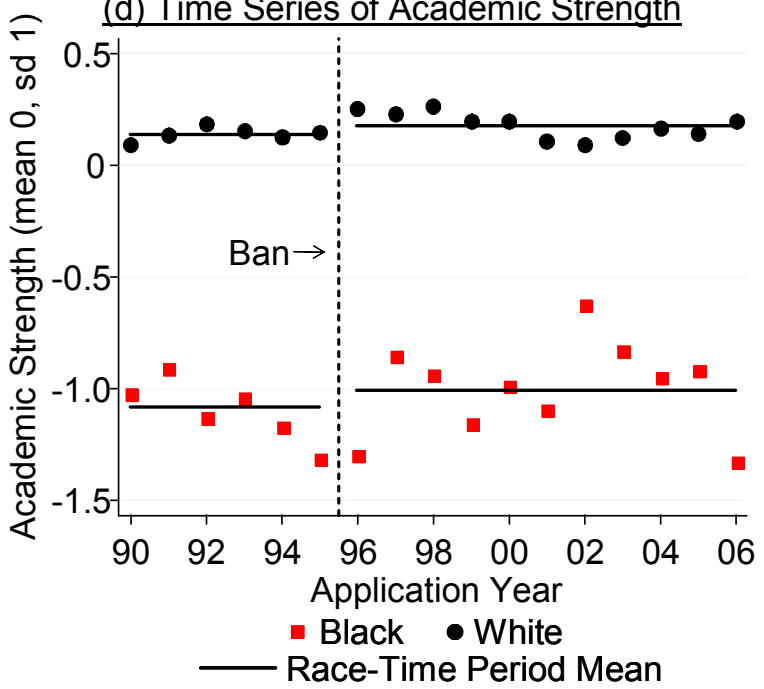

Notes - This figure displays the student-level distribution of academic credentials by race in the paper's EALS analysis sample. LSAT is the standardized test score used in law school admissions and ranges from 120 to 180 . Undergraduate grade point average is the cumulative undergraduate GPA on a 4.00 scale. Academic strength is a scalar index of the strength of an applicant's academic credentials, equal to the standardized (mean zero and standard deviation one) sum of standardized LSAT and standardized GPA (see Figure 2). Each displayed density is estimated non-parametrically using an Epanechnikov kernel with Silverman bandwidth. Application year refers to the autumn of the application year. 


\section{ONLINE APPENDIX FIGURE 4 \\ Scatterplot of 23,128 Admission Decisions at Non-UC Schools}

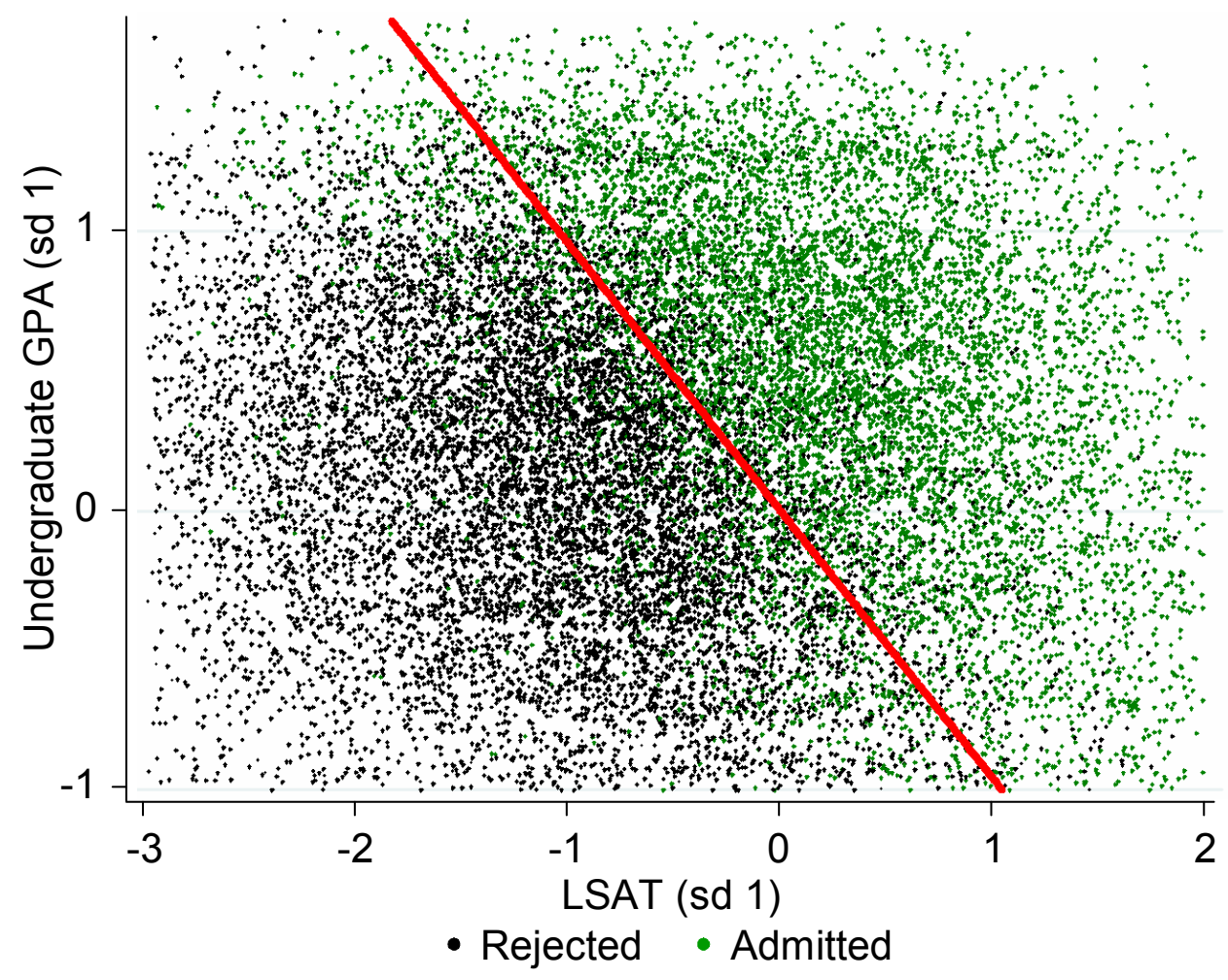

Notes - This figure is intelligible only in color. It replicates Figure 2a except that it plots all 23,128 applications to non-UC schools, rather than just a 5\% random sample. See the notes to that figure for details. 


\section{ONLINE APPENDIX FIGURE 5 \\ Inferred Strength and Admission Rates}

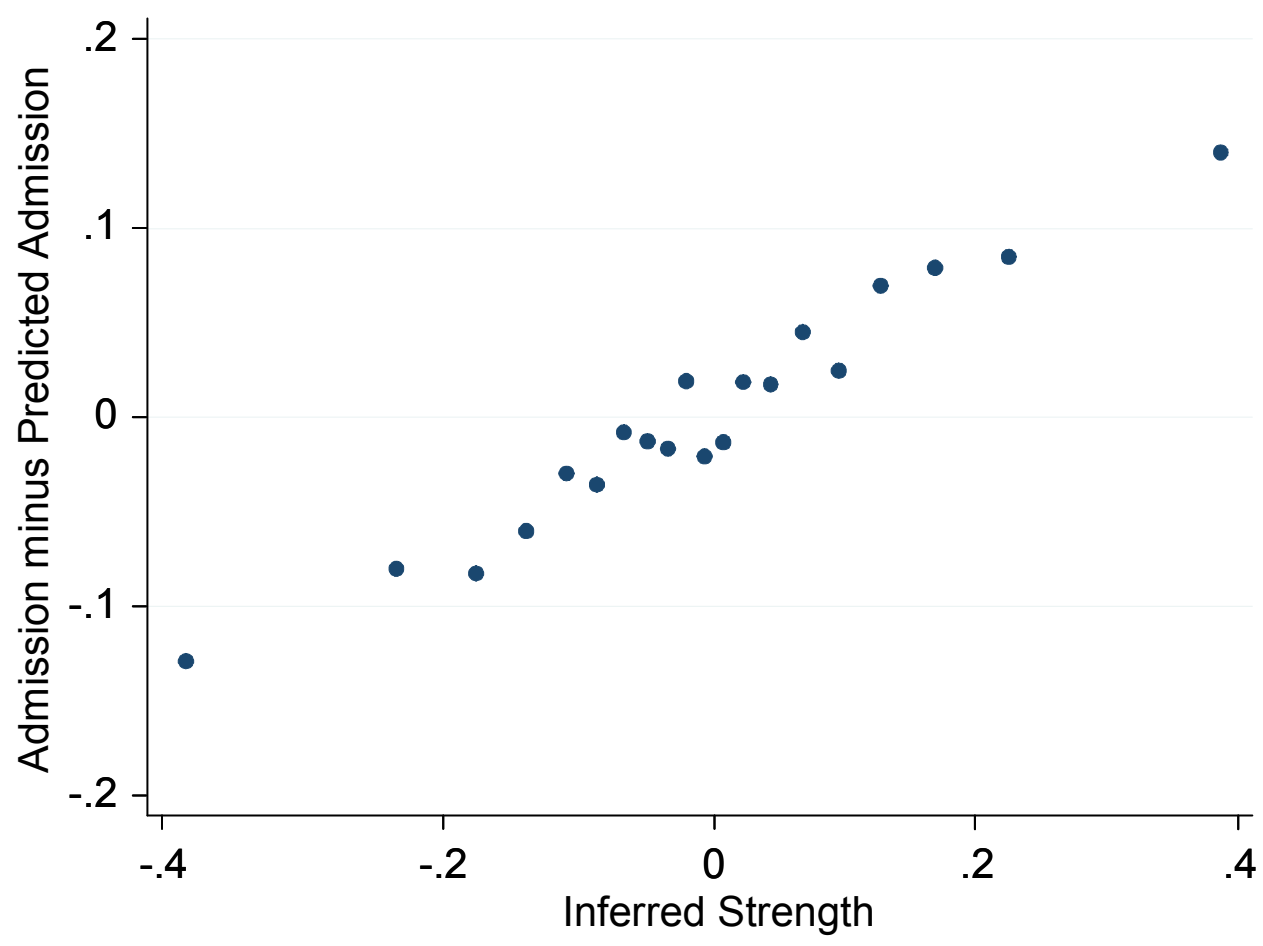

Notes - This graph displays the ability of the inferred strength variable (motivated by Dale and Krueger 2002) to predict admission, conditional on other covariates. I proxy for unobserved admission determinants using the intuition that if an applicant predicted to be rejected based on LSAT, GPA, and race is in fact consistently admitted across schools in the EALS, this applicant is likely strong on commonly-valued unobserved characteristics like recommendation letters. Specifically I construct the inferred strength variable for an application submitted by student $i$ to school $s$ equal to the mean across all applications submitted by student $i$ to schools other than $s$ of residuals from within-school probit regressions of admission on LSAT, GPA, race indicators, and time-period fixed effects (see Section III.D). Then to construct this illustrative graph, I compute inferred strength residuals from an ordinary least squares regression of inferred strength on LSAT, GPA, race, and school-year fixed effects, and I compute admission residuals from a probit regression of admission on the same covariates. I then group applications into twenty equal-sized (five-percentile-point) bins based on the inferred strength residuals and plot mean admission residuals within each bin. 


\section{ONLINE APPENDIX FIGURE 6 Admissions under an Affirmative Action Ban}

(a) Affirmative Action

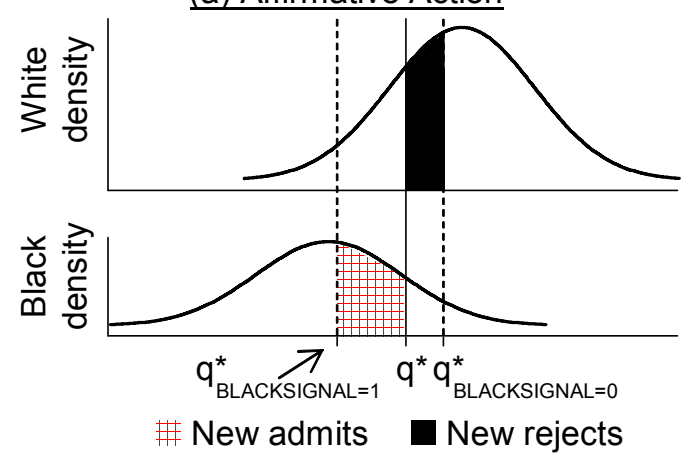

(b) Affirmative Action Ban

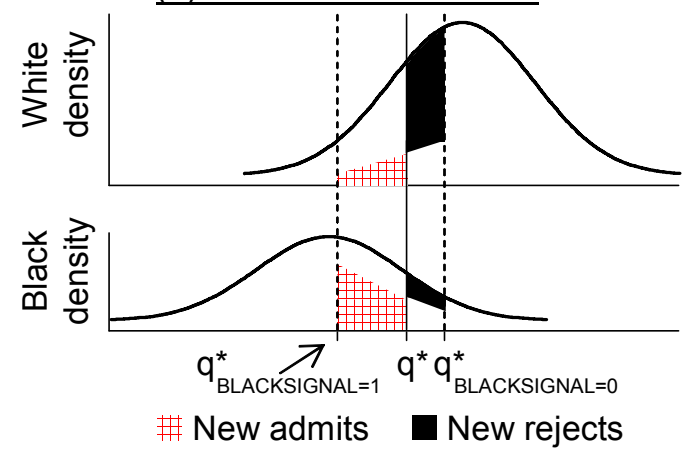

(c) Optimal Bundles

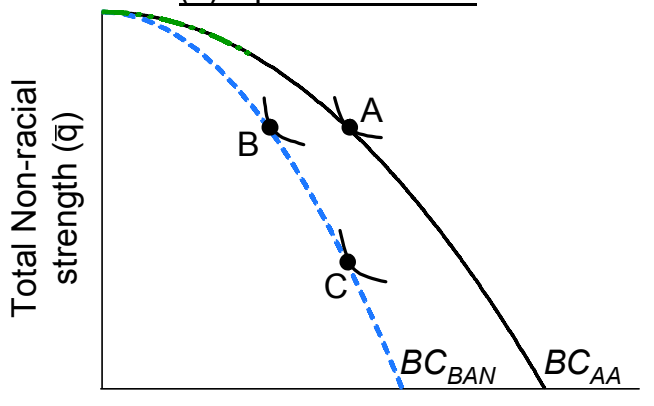

Total black admits $(\bar{r})$

Notes - This figure illustrates the simple model of admissions under an affirmative action ban presented in Appendix A in which the applicant pool is held fixed and the school has concave preferences over the number of black applicants enrolled and the aggregate non-racial strength of the enrolled cohort. The school can admit applicants on two pieces of applicant information: non-racial strength and a signal of black status. Panels (a) and (b) depict applicant densities in non-racial strength; "new" refers to the effects of placing positive weight on the black signal. Panel (c) plots budget sets under the simplification of uniform distributions of non-racial strength. The graph omits feasible but always-dominated bundles by defining the x-intercept as the number of black applicants admitted if the school were to maximize only non-racial strength and the $y$-intercept as the aggregate non-racial strength achieved if the school were to maximize only the number of admitted blacks. Under affirmative action (AA), the black signal is pure. Under an affirmative action ban (Ban), the usable black signal available to the school is impure, so the school faces a higher opportunity cost (in terms of non-racial strength) of admitting black students. It therefore changes its optimal bundle from a bundle like A to some bundle on the interior budget set depending on whether substitution effects (e.g. bundle B) or income effects (e.g. bundle C) dominate. 